\title{
THE MYOSIN MOTOR DOMAIN-CONTAINING CHITIN SYNTHASE PdChsVII IS REQUIRED FOR DEVELOPMENT, CELL WALL INTEGRITY AND VIRULENCE IN THE CITRUS POSTHARVEST PATHOGEN Penicillium digitatum.
}

Mónica Gandía *, Eleonora Harries and Jose F. Marcos

Food Science Department, Instituto de Agroquímica y Tecnología de Alimentos (IATA), Consejo Superior de Investigaciones Científicas (CSIC), Avda Agustín Escardino 7, 46980 Paterna, Valencia, Spain

* Address for correspondence: Dr. Mónica Gandía. Instituto de Agroquímica y Tecnología de Alimentos (IATA) - CSIC, Avenida Agustín Escardino 7 , Paterna 46980, Valencia, Spain. e-mail: mgandia@iata.csic.es. Phone: (34)963.900.022. Fax: (34)963.636.301 

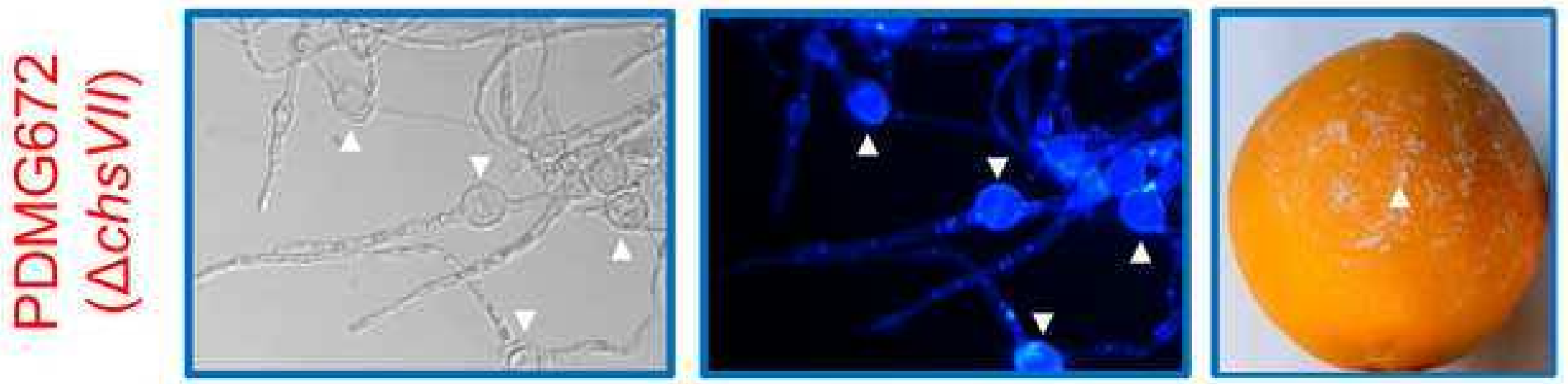

苍
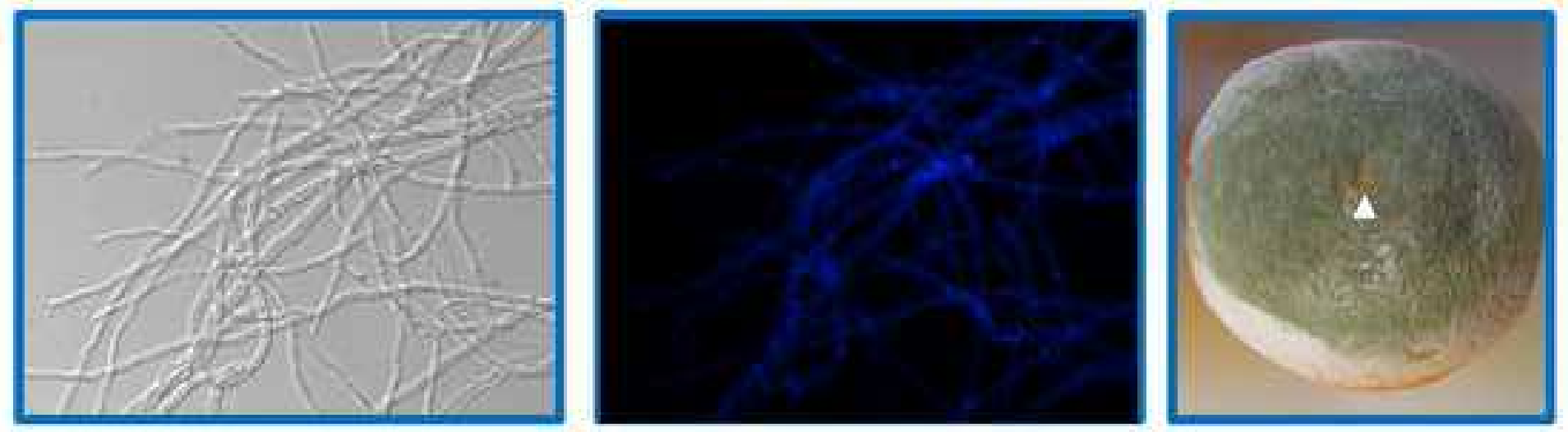


\section{Highlights}

- chs genes from $P$. digitatum are grouped into seven classes and three divisions

- Disruption of the PdchsVII containing a myosin motor domain was carried out

- PdchsVII mutants showed altered CW and increased sensitivity to antifungal compounds

- PdchsVII mutants had reduced virulence and defects in development on citrus fruit

- Gene expression analysis supported compensatory effects between different chs 


\section{Abstract}

Chitin is an essential component of the fungal cell wall and a potential target in the development of new antifungal compounds, due to its presence in fungi and not in plants or vertebrates. Chitin synthase genes (chs) constitute a complex family in filamentous fungi and are involved in fungal development, morphogenesis, pathogenesis and virulence. In this study, additional chs genes in the citrus postharvest pathogen Penicillium digitatum have been identified. Comparative analyses included each PdChs in each one of the classes I to VII previously established, and support the grouping of these into three divisions. Disruption of the gene coding PdChsVII, which contains a short version of a myosin motor domain, has been achieved by using Agrobacterium tumefaciensmediated transformation and revealed its role in the life cycle of the fungus. Disruption strains were viable but showed reduced growth and conidia production. Moreover, Pdchs mutants developed morphological defects as balloon-like enlarged cells and increased chitin content, indicative of an altered cell wall structure. Gene disruption also increased susceptibility to antifungal compounds such as calcofluor white (CFW), sodium dodecyl sulfate (SDS), hydroxide peroxide $\left(\mathrm{H}_{2} \mathrm{O}_{2}\right)$ and commercial fungicides, but significantly no change was observed in the sensitivity to antifungal peptides. The PdchsVII mutants were able to infect citrus fruit and produced tissue maceration, although had reduced virulence and most importantly were greatly impaired in the production of visible mycelium and conidia on the fruit.

Keywords: Chitin synthase; cell wall; Penicillium digitatum; postharvest pathology; citrus. 


\section{Introduction}

The search for new antifungal compounds with novel targets that could efficiently control fungal microorganisms constitutes an important challenge due to the emergence of mycosis in medicine, the importance of fungal plant pathogens for crop production and agriculture, and the contamination of food by fungi and yeast that cause food spoilage.

The fungal cell wall $(\mathrm{CW})$ is a protective and reactive structure that constitutes the first line of interaction of the fungus with the environment, outer surfaces and host cells, having also great plasticity after sensing environmental changes. Fungal CW is composed by different connected polysaccharides and glycoproteins, being the core structure common to all fungi a branched $\beta-1,3$ glucan-chitin network (Behr, 2011; Latgé, 2007). Chitin is a microfibrillar homopolymer of lineal $\beta$-1,4-linked N-acetylglucosamine (GIcNAc) (Lenardon et al., 2010; Merzendorfer, 2011). It is considered a quantitatively minor but structurally important and essential constituent of the fungal CW. Importantly, chitin is not present in plants or animal cells and is, therefore, an important target to develop new antifungal drugs against plant or animal fungal pathogens (Latgé, 2007; Lenardon et al., 2010). In addition, host immune responses are activated when plants or animals recognize chitin presence, and for this reason chitin is considered as a pathogen-associated molecular pattern important in the host-pathogen interaction (Kombrink et al., 2011).

Chitin synthases (Chs) are membrane integral glycosyl-transferases that transfer the sugar moiety of activated UDP-GIcNAc to the growing chitin chain. Fungal Chs constitute a complex protein family with up to 20 members in some 
fungus, and have been classified in seven classes (classes I to VII) with at least one member from each class in most filamentous fungi (Kong et al., 2012; Latgé, 2007; Lenardon et al., 2010; Niño-Vega et al., 2004; Roncero, 2002). In this study, we have followed the classification proposed in recent reviews (Lenardon et al., 2010; Merzendorfer, 2011; Roncero, 2002). The general consensus has been to group the seven Chs classes into two Divisions ( 1 and 2). However, class VI proteins were noted to have a distinctive topology and Pfam domain structure (Choquer et al., 2004; Latgé, 2007) and be distantly related to the other classes that form Division 2 (Larson et al., 2011; MartínUrdíroz et al., 2008); therefore a third Division was proposed (Latgé, 2007). Importantly, classes III, V, VI and VII are exclusive of filamentous fungi and not present in yeast, which is probably as a consequence of their higher chitin content and more complex morphology that would require additional synthesis machinery (Niño-Vega et al., 2004; Roncero, 2002).

The classes V and VII include the largest Chs due to the presence of a myosin motor-like domain (MMD) at their N-terminal region (Latgé, 2007; Merzendorfer, 2011; Rogg et al., 2012). There are two different MMD domains in Chs: Class V Chs have a MMD domain containing conserved ATP-binding motifs (P-loop, Switch I and Switch II) while class VII proteins have a shorter MMD domain without ATP-binding sequences (Niño-Vega et al., 2004; Takeshita et al., 2006). Deletion of a number of these MMD-Chs from different fungi demonstrated their involvement in fungal morphology, development, sensitivity to different antifungals drugs, virulence and pathogenicity (Cui et al., 2013; Horiuchi et al., 1999; Kim et al., 2009; Larson et al., 2011; Martín-Urdíroz et al., 2008; Schuster et al., 2012; Steinberg, 2011; Treitschke et al., 2010; Weber et al., 2006; 
Werner et al., 2007). In addition, the myosin domain of class $V$ has been related to actin binding and polar localization (Takeshita et al., 2005; Treitschke et al., 2010). On the contrary, it has been demonstrated that either class V or class VII are dispensable to virulence in some fungi that include phytopathogens (Aufauvre-Brown et al., 1997; Cui et al., 2009; Kong et al., 2012). Therefore, further research is needed to better characterize the role of MMD-containing Chs and include fungi of lifestyles different to the ones studied so far. The citrus postharvest pathogen Penicillium digitatum is a necrotrophic filamentous fungus specific of citrus, that causes green mold and postharvest decay specifically in citrus fruit, infecting through pre-existing wounds and producing very important economic losses in one of the main fruit tree crops worldwide (Macarisin et al., 2007; Marcet-Houben et al., 2012). The main method to control citrus postharvest decay is the use of chemical fungicides (Holmes and Eckert, 1999), which has obvious disadvantages derived from unspecific toxicity. Moreover, the massive use of a limited spectrum of commercial fungicides in citrus industry has boosted the selection of resistant isolates that pose at risk worldwide citrus commercialization for fresh consumption (Holmes and Eckert, 1999; Sun et al., 2011). These problems have led to the search for new alternatives to the control of this and other fungi, as for example the use of antifungal peptides (Marcos et al., 2008). PAF26 is a model synthetic hexapeptide that has specific cell-penetration and antifungal activity (Muñoz et al., 2013a). We had observed that $P$. digitatum and Saccharomyces cerevisiae cells exposed to PAF26 showed increased staining with the chitin specific dye calcofluor white (CFW) (López-García et al., 2010; Muñoz et al., 2006). Additional studies have revealed a role of chitin and chs 
genes in the activity of antifungal peptides and proteins (Hagen et al., 2007; Martín-Urdiroz et al., 2009; Ouedraogo et al., 2011). Therefore we decided to initiate the study in $P$. digitatum of the potential connections between chs genes, on one hand, and development, pathogenicity and sensitivity to fungicides and antifungal peptides, on the other.

Previously, five different chitin synthase genes in $P$. digitatum were identified and their gene expression characterized (Gandía et al., 2012). The recent sequencing of the genome of $P$. digitatum (Marcet-Houben et al., 2012) allowed the identification of additional chs genes in this fungus, as described below. In this study, the functional characterization of the MMD-containing chitin synthases in $P$. digitatum was also initiated through the disruption of PdchsVII gene by Agrobacterium tumefaciens-mediated (ATMT) transformation. The characterization of disruption mutants revealed the importance of PdChsVII for fungal morphology and CW integrity, and also to mycelium development during fruit infection in this necrotrophic fungus. 


\section{Material and methods}

\subsection{Microorganism, media and culture conditions}

Penicillium digitatum strain CECT20796 (isolate PHI26) (López-García et al., 2000; Marcet-Houben et al., 2012) was used as fungal parental isolate for transformation. This strain and all transformants generated in this work were routinely cultured on potato dextrose agar (PDA) (Difco 213400) plates for 7-10 days at $24{ }^{\circ} \mathrm{C}$. For analysis of growth, $5 \mu \mathrm{L}$ of conidial suspension $\left(1 \times 10^{3}\right.$ conidia/mL) of each $P$. digitatum strain were spotted on the centre of PDA plates and monitored daily. To determine conidia production, conidia were collected, filtered and counted with a hemacytometer at intervals of 3,4 and 6 days, and normalized to the surface of the fungal colony. For liquid growth, CECT20796 and transformants were grown in $100 \mathrm{~mL}$ of potato dextrose broth (PDB) (Difco 254920) at $24^{\circ} \mathrm{C}$ with shaking.

Agrobacterium tumefaciens AGL-1 strain was grown in Luria Bertani medium (LB) supplemented by $20 \mu \mathrm{g} / \mathrm{mL}$ rifampicin at $28^{\circ} \mathrm{C}$.

\subsection{Sequence and phylogenetic analysis}

Sequences from chs genes were obtained and homology analyses carried out at the National Center for Biotechnology Information server (http://www.ncbi.nlm.nih.gov) (Supplemental Table 1). Sequence analyses using profile hidden Markov models (HMM) was conducted at the HMMER server (http://hmmer.janelia.org/) (Finn et al., 2011). Multiple sequence alignments were carried out with the ClustalW algorithm (Thompson et al., 1994) (http://www.ebi.ac.uk/Tools/clustalw2/index.html). The phylogenetic tree was obtained with the Neighbor-Joining method (Saitou and Nei, 1987) using 
the MEGA 5.2. program (Tamura et al., 2011). Nucleotide distances were estimated using the $p$-distances method and a bootstrap values were computed using 10,000 replicates.

\subsection{Construction of gene disruption vector and fungal transformation}

All PCR procedures were carried out with AccuPrime High Fidelity polymerase (Invitrogen 12346-086), and all the resulting DNA constructs were verified by DNA sequencing. Fusion PCR (Szewczyk et al., 2006) was used to generate a construct to disrupt the PdchsVII by homologous recombination. The primers used are listed in Supplemental Table 2. The hygromicin resistant cassette (hph) used as positive selection marker was amplified from pBHt2 (Khang et al., 2006) with primers OJM197 and OJM198. It was flanked by fungal DNA fragments of $1221 \mathrm{bp}$ (primers OJM230 and OJM213) and $1131 \mathrm{bp}$ (primers OJM214 and OJM228) amplified from $P$. digitatum CECT20796 genomic DNA. The fusion PCR fragment obtained was purified and ligated into pGEM-T Easy vector System I (Promega A1360). BamHI and HindIII restriction was used to insert the construct into the binary vector pGKO2 (Khang et al., 2006), which also contains between the LB and RB of T-DNA, the Herpes Virus tiamine kinase gene (HSVtk) used as negative selection marker, and obtain the plasmid pGKO2_AchsVII. This binary vector was transformed into A. tumefaciens AGL-1 strain.

Penicillium digitatum strain CECT20796 was transformed with pGKO2_AchsVII through A. tumefaciens-mediated transformation (ATMT) as described previously (Khang et al., 2006; Michielse et al., 2008) with minor modifications (Harries et al., 2013, manuscript in preparation). Essentially, transformants were 
first selected in $50 \mu \mathrm{g} / \mathrm{mL}$ hygromicin B (Invivogen, ant-hm-5) and then in $10 \mu \mathrm{M}$ 5-fluoro-2-deoxyuridine (F2dU) (Sigma-Aldrich F0503)

Transformants were checked by PCR amplification of genomic DNA. Fungal mycelium grown for 7 days in PDB was used to extract genomic DNA (Khang et al., 2006). PCR was carried out with different primers (Supplemental Table 3) located at different positions in the target locus and the disruption construct (see Supplemental Fig. 1). PCR amplifications were carried out in $50 \mu \mathrm{L}$ reactions that included $100 \mathrm{ng}$ of genomic DNA, $0.1 \mathrm{mM}$ of each primer, $0.1 \mathrm{mM}$ of dNTPs, $1.5 \mathrm{mM}$ of $\mathrm{MgCl}_{2}$, and $1.25 \mathrm{U}$ of Taq DNA polymerase (Ecogen ETAQ500). The PCR profile consisted in 35 cycles at $94^{\circ} \mathrm{C}$ for $1 \mathrm{~min}, 60^{\circ} \mathrm{C}$ for $2 \mathrm{~min}$, and $72{ }^{\circ} \mathrm{C}$ for $1 \mathrm{~min}$, and a final extension of $72^{\circ} \mathrm{C}$ for $10 \mathrm{~min}$. Size and presence of DNA amplicons were determined by gel electrophoresis.

\subsection{Total RNA extraction and quantitative RT-PCR}

Total RNA from (i) time course experiments of $P$. digitatum strains grown in PDB or PDA or (ii) infected fruit samples, was obtained following previously described procedures (Ballester et al., 2006; Gandía et al., 2012; Rodrigo et al., 2004). Two $\mu g$ of RNA treated with RNase-free DNase according to the manufacturer's instructions (Ambion AM1906), were used to synthesize first strand cDNA using $200 \mathrm{U}$ of SuperScript III reverse transcriptase (Invitrogen 18080-044) and $0.5 \mu \mathrm{g}$ of an oligo(dT)12-18 primer (Invitrogen 18418-012) according to manufacturer's protocol in the presence of $20 \mathrm{U}$ of RNase inhibitor (Roche Diagnostics 03335399001 ), at $50^{\circ} \mathrm{C}$ for 90 min. cDNA samples were diluted eight times with nuclease-free water. 
Gene specific primers used for qRT-PCR are shown in Supplemental Table 4. Quantitative PCR was performed as described (Gandía et al., 2012). Briefly, results shown are mean of two biological replicates and three technical replicates for each biological replicate. Genes coding for $P$. digitatum $\beta$-tubulin (Sanzani et al., 2009), ribosomal protein L18a (González-Candelas et al., 2010), and 18S rRNA (Nair et al., 2009) were simultaneously used as independent reference genes (Supplemental Table 4). The algorithm geNorm (Vandesompele et al., 2002) demonstrated expression stability of these reference genes under our experimental conditions. The quantification cycle point $(\mathrm{Ct})$ was obtained using the software LightCycler 480 SW 1.5 (Roche Diagnostics). The Relative Expression Software Tool (Multiple Condition Solver REST-MCS v2) (Pfaffl et al., 2002) was used to determine the relative quantification of target genes normalized to the reference genes, and the REST 2009 software (http://www.genequantification.de/rest-2009.html) to determine statistical significance.

\subsection{Sensitivity of fungal strains to chemicals and temperature}

To test sensitivity of fungal strains to chemicals, PDA medium was supplemented with different concentrations of $\mathrm{H}_{2} \mathrm{O}_{2}$, calcofluor white (CFW) (Fluorescent Brightener 28, Sigma-Aldrich, F3543), sodium dodecyl sulphate (SDS Sigma-Aldrich L4509), or Congo red (CR Sigma-Aldrich, C6767). Cell culture microtiter plates of 24 wells were used ( $1 \mathrm{~mL}$ medium per well) and incubated at $24^{\circ} \mathrm{C}$ for 3-4 days. Five $\mu \mathrm{L}$ of serial 10 -fold dilution of conidia $\left(1 \times 10^{5}\right.$ to $\left.1 \times 10^{3}\right)$ were applied into each well. 
Similarly, sensitivity to different temperatures was tested by incubating strains in 24-well plates at $24^{\circ} \mathrm{C}, 28^{\circ} \mathrm{C}$ and $32^{\circ} \mathrm{C}$ for 3-days.

Sensitivity to fungicides and antifungal peptides was tested in 24-well plates containing one fourth diluted PDB and $1.4 \%$ agarose low EEO (Pronadisa 8016), amended with different concentrations of the fungicides thiabendazole (TBZ) (Sigma-Aldrich, T5535) and imazalil (IMZ) (Riedel de Haën, 45530) or the antifungal peptide PAF26. PAF26 (amino acid sequence RKKWFW) was synthesized and provided at $>95 \%$ purity by GenScript Corporation (Piscataway, NJ, USA). Agarose was used instead of agar to solidify the media because PAF26 is not active in the presence of agar. Five $\mu \mathrm{L}$ of one fourth dilutions of conidia suspensions $\left(1.56 \times 10^{4}\right.$ to $\left.9.75 \times 10^{2}\right)$ were applied into each well. Plates were incubated at $24^{\circ} \mathrm{C}$ for $3-5$ days.

\subsection{Fluorescence microscopy}

Cultures $\left(2.5 \times 10^{4}\right.$ conidia/mL $)$ of $P$. digitatum strains were grown in $5 \%$ PDB containing $30 \mu \mathrm{g} / \mathrm{mL}$ chloramphenicol to avoid bacterial contamination, for $48 \mathrm{~h}$ at $24{ }^{\circ} \mathrm{C}$. Once grown, the mycelium was stained with $\mathrm{CFW}$ to a final concentration of $10 \mu \mathrm{g} / \mathrm{mL}$ for 5 min in darkness, washed and suspended in $20 \%$ glycerol solution. The CFW fluorescence was visualized in a fluorescence microscope E90i (Nikon) with excitation and emission wavelengths of $395 \mathrm{~nm}$ and $440 \mathrm{~nm}$, respectively. The images were captured with a $40 \mathrm{X}$ objective using the software NIS-Elements BR v2.3 (Nikon). 


\subsection{Cell-wall chitin content}

Chitin content of fungal mycelia was measured as described (Din et al., 1996; Muñoz et al., 2011) with minor modifications. PDB cultures were inoculated with $2 \times 10^{5}$ conidia/mL of $P$. digitatum strains and grown at $24^{\circ} \mathrm{C}$ for 7 days. Digestion was carried out with $0.22 \mathrm{U}$ of Streptomyces griseus chitinase suspension (Sigma-Aldrich C6137) and $5 \mathrm{U}$ of Zymolyase 20T (Euromedex UZ1000). Four replicates were carried out and significance was determined by t-test statistical analysis $(p<0.05)$.

\subsection{Fruit infection assays}

Freshly harvested fruits of mature orange (Citrus sinensis L. Osbeck) from the cultivar 'Navelina' were used throughout this study. Inoculation and sample collection were carried out as described previously (González-Candelas et al., 2010). Fruits were inoculated at four wounds around the equator. Each inoculated wound was scored for green mold infection symptoms at different days post-inoculation (dpi). At 1, 2, 4 or 7 dpi tissue discs of $5 \mathrm{~mm}$ in diameter around the inoculation site were sampled. 


\section{Results}

\subsection{Identification of chitin synthase genes in P. digitatum and their classification in three major divisions}

Five different chitin synthase genes from classes I, II, III, V and VII were previously identified in $P$. digitatum and their gene expression was characterized (Gandía et al., 2012). The recent sequencing of the $P$. digitatum genome (Marcet-Houben et al., 2012) allowed the identification of two additional Chs that belong to classes IV and VI (Table 1). Phylogenetic tree reconstruction using Chs enzymes from filamentous fungi, yeast and insects (Fig. 1A) and domain structure prediction of the Chs from $P$. digitatum (Fig. 1B) supported the grouping of the Chs from fungi in three major divisions: Division 1 that includes classes I, II and III; Division 2 including classes IV, V, and VII; and Division 3 with class $\mathrm{VI}$, that is more closely related to insect Chs. The enzymes that belong to Division 1 share the presence of the Pfam chitin synthase domains $1 \mathrm{~N}$ (PF08407) and 1 (PF01644) located at the N-terminal half of the protein, while Divisions 2 and 3 contain the Pfam chitin synthase domain 2 (PF03142). Division 2 chitin synthases are known to contain a cytochrome b5-like domain (PF00173), which according to the predicted topology of transmembrane helices (TMH) would be located at the opposite membrane side of the chitin synthase domains and at the same side as the MMD (PF00063). Both the MMD and the cytochrome b5 domains are of different length in the different classes of Chs. In addition, the MMD Chs also contain a C terminal domain (PF08766) found in the cancer associated human DEK protein (Devany et al., 2004). 


\subsection{Disruption of PdchsVII in P. digitatum}

Our preliminary gene expression analyses indicated that the expression of the MMD genes $P d c h s V$ and $P d c h s V I I$ was more increased during fungal infection than during growth in liquid culture (see also below). Therefore we aimed to generate mutants in these genes to investigate their roles during fungal growth and pathogenesis.

To disrupt PdchsVII gene, homologous recombination was used to replace a portion of the $5^{\prime}$ region of the PdchsVII ORF with the hph cassette as positive selection marker (Supplemental Fig.1A). The binary vector pGKO2__chsVII contains the disruption construct and also the HSVtk gene used as negative selection marker to favor the selection of homologous recombinants by discarding ectopic insertions (Khang et al., 2005). P. digitatum strain CECT20796 was transformed by $A$. tumefaciens AGL-1 harbouring pGKO2_AchsVII. A number of 799 P. digitatum transformants resistant to hygromycin B were obtained and then analysed for resistance to F2dU, a compound that results lethal in the presence of the HSVtk gene. Fifty five strains were resistant to hygromycin B and F2dU, but only two of them showed homologous recombination at the desired locus: strains PDMG439 and PDMG672 (Supplemental Fig. 1B-F).

The disruption of class VII chitin synthase gene was confirmed by a complete set of PCR amplifications using specific primer combinations (Supplemental Table 3) to discriminate disruption transformants from ectopic insertions and parental genotypes (Supplemental Fig. 1B-F). Some of these primers were located outside the target gene and others were located inside the $h p h$ or the 
HSVtk cassettes (Supplemental Fig. 1A). It was concluded that two disruption mutants, PDMG439 and PDMG672, were obtained and that PDMG439 contains an additional ectopic insertion of the T-DNA. Further characterization confirmed that both PDMG439 and PDMG672 share very similar phenotypes (see below).

\subsection{Reduced growth and conidiation of PdchsVII mutants}

The growth and conidia production of the disruption strains PDMG672 and PDMG439 were characterized and compared with the CECT20796 parental strain and the PDMG612 ectopic transformant as controls (Fig. 2). PDMG672 and PDMG439 showed reduced mycelial growth on PDA plates while PDMG612 exhibited a growth rate similar to that of the parental (Fig. 2A and B). The growth of disruption mutants in liquid PDB was also slower and more disperse than controls, not forming large or dense clots of mycelium (data not shown). Reduced growth was recovered in the presence of $1.2 \mathrm{M}$ sorbitol as osmotic stabilizer (Fig. 2B and C). Strains PDMG672 and PDMG439 showed, in addition, a delay in conidia production that was also restored during growth under osmotic stabilization (Fig. 2A and D).

Morphology of PDMG672 and PDMG439 hypha was analysed by fluorescence microscopy under CFW staining. In spite of the delayed conidia production, the conidia or conidiophores produced by PdchsVII mutants did not show morphological differences in comparison with parental or ectopic strains (data not shown). The mycelium of mutant strains showed dispersed swellings and balloon-like enlarged cells that appeared more stained with CFW than surrounding cells (Fig. 3A), revealing altered CW structure and/or chitin deposits in these disruption mutants. These balloon structures were visible even 
under the stereomicroscope at low magnification as discrete pearls in the mycelial filaments, and were conserved in strains grown with osmotic stabilization (data not shown). The CFW staining in PDMG672 and PDMG439 mutants was more intense than in the parental strain (Fig. 3A), and correlated with significantly higher chitin content in mutants (Fig. 3B).

3.4. Increased susceptibility of PdchsVII mutants to antifungal chemicals and temperature stress

We examined the effect of the disruption of PdchsVII on the sensitivity to different compounds and growth conditions. To further investigate the $\mathrm{CW}$ integrity of mutants, the sensitivity to the CW interfering agents CFW (Fig. 4A), SDS (Fig. 4B), and Congo red (data not shown) was studied. PDMG672 and PDMG439 exhibited increased sensitivity to these compounds, confirming a defective CW. This conclusion was additionally supported by the increased sensitivity of strains PDMG672 and PDMG439 to temperatures higher than the optimal $24^{\circ} \mathrm{C}$ (Fig. 4C). In all the experiments, the ectopic transformant PDMG612 used as control behaved similarly to the parental strain (Fig. 4C and data not shown).

It was also tested the sensitivity to $\mathrm{H}_{2} \mathrm{O}_{2}$ as representative of the reactive oxygen species (ROS) that are produced in many plant-pathogen interactions (Fig. 4D). Both disruption mutants showed increased sensitivity to $\mathrm{H}_{2} \mathrm{O}_{2}$. In this case the ectopic transformant PDMG612 also showed limited increase in sensitivity to ROS.

Finally, it was analyzed the sensitivity to the commercial fungicides TBZ and IMZ that are used during postharvest conservation, and also to various 
antifungal peptides. Disruption strains were more affected by IMZ and TBZ than parental or ectopic strains (Fig. 5A), but did not show obvious differences in sensitivity to the antifungal peptide PAF26 compared to CECT20796 (Fig. 5B). Also, other antimicrobial and antifungal peptides with different modes of action such as melittin (Terwillinger and Eisenberg, 1982), cecropin A (Steiner et al., 1981) or P113 (Jang et al., 2008) was also assayed (data not shown), and PDMG672 and PDMG439 strains did not show changes of sensitivity compared to the parental strain.

\subsection{Gene expression analyses indicate compensatory changes in PdchsVII mutants}

Relative gene expression was analyzed in parental and disruption PDMG672 and PDMG439 strains during growth in liquid PDB (Fig. 6A and Supplemental Fig. 2) or in solid PDA (Fig. 6B). Quantitative RT-PCR was carried out for the seven chitin synthase genes and normalized simultaneously with three reference genes (see Material and Methods). Transcript of PdchsVII was assayed with primers OJM310/325 (Supplemental Table 4) and was found in the parental strain but not in PDMG672 or PDMG439 as expected. In the parental strain, gene expression of the five previously reported $P d c h s$ genes (classes I, II, III, V, and VII) were fairly constant during growth in PDB (Fig. 6A), similarly to the previously reported experiments (Gandía et al., 2012). Notoriously, the novel PdchsIV followed by PdchsVI were the genes that presented the highest induction during growth of CECT20796.

Statistical analyses showed that disruption of PdchsVII had effect on the expression of other Pdchs during growth in liquid PDB (Fig. 6A). A substantial 
induction of $P d c h s / l$ and $P d c h s V I$ expression was detected in the PDMG672 mutant compared with the parental strain and also it was reproduced in the PDMG439 mutant (Supplemental Fig. 2). The gene showing the largest increase of expression in both PDMG672 and PDMG439 was Pdchsll, which was induced up to 50-fold during growth, while in CECT20796 remained almost constant or even declined. Expression of PdchsIV, PdchsV and PdchsVI genes was also induced in disruption mutants compared to the parental strain, ranging from 2 to 5 times depending on the gene, time of growth, mutant strain and experiment (Fig. 6A and Supplemental Fig. 2). Expression of Pdchs/ and Pdchs/ll remained at similar levels in the mutant and parental strains. Gene expression changes during growth in solid PDA medium were qualitatively different from changes during growth in PDB (Fig. 6B). The genes showing the largest induction in the parental strain were PdchsVI and Pdchsll. The induction of this latter was reported previously and correlated with conidia production that starts at 4 days of growth (Gandía et al., 2012). Expression changes of the different $P d c h s$ did not show dramatic changes in the disruption strains (Fig. 6B), and only Pdchs// transcript reached a significant higher level at 7 days of growth.

Gene expression was determined in the presence of the osmotic stabilizer 1.2 M sorbitol (Fig. 7). In the parental strain, all the chs genes showed reduced expression with sorbitol that was statistically significant in Pdchs/l and PdchsVI. In the PDMG672 mutant, the expression of these latter two genes was significantly induced by the presence of sorbitol, especially in Pdchs/l whose induction reached 4-8 times the control value. 


\subsection{PdchsVII mutants have reduced virulence on citrus fruit}

To determine the pathogenicity of the PdchsVII disruption mutants, infection assays were performed by inoculating citrus fruits with conidial suspensions (Fig. 8). Low inoculum doses $\left(10^{4}\right.$ conidia/mL) demonstrated that the disruption mutants PDMG672 and PDMG439 had a reduced virulence because showed an incidence of infection lower than the parental strain CECT20796 or the ectopic control PDMG612 (Fig. 8A). Also, the disruption mutants displayed a reduced rate of progression of the maceration area (data not shown). At this low inoculum dose, maceration of tissue around the inoculation site caused by CECT20796 began to appear after 3 dpi; at 4-5 days white mycelium was visible within the maceration area that continued to expand; and from 5 days onwards, the green sporulation characteristic of $P$. digitatum decay appeared. In these fruits, the infection border was followed by a small front of tissue maceration, then by a zone in which white mycelium was clearly visible and finally by a green sporulation area centered at the inoculation point that grew with time. Only $40-50 \%$ of wounds became infected with CECT20796, while none of the two disruption mutants went over $20 \%$ of infection (Fig. 8 A). In addition, the experiments did not show either visible mycelium or green conidia in fruits inoculated with the disruption mutants (data not shown). Since this latter result could be due to the low inoculation dose used and the reduced virulence of the mutants, we decided to explore it further.

In our laboratory we use high inoculum doses $\left(10^{6}\right.$ conidia/mL) to synchronize infection in all the inoculated wounds (González-Candelas et al., 2010). At this conidia concentration the infection develops so quickly and sharply that at $2 \mathrm{dpi}$ 
there are no visible symptoms ( $0 \%$ incidence of infection) while at $3 \mathrm{dpi}$ all the wounds (100\%) are infected and develop uniformly thereafter (Fig. 8B). Under these conditions, the incidence of infection (Fig. 8B) and the progression rate of the macerated area (Fig. 8C) were the same in CECT20796 and PDMG672. Moreover, qRT-PCR measurements of fungal mRNA housekeeping genes confirmed that fruit colonization was significantly different in the parental strain and the mutant under this high inoculum dose (Fig. 8D). However, infection of PDMG672 could only be identified as an expanding maceration area over the fruit peel that rarely developed white mycelium or even green sporulation (Fig. $8 \mathrm{E}$ and $8 \mathrm{~F})$. At the end of the experiment ( $7 \mathrm{dpi})$ the fruits inoculated with PDMG672 had all the maceration area covering the fruit and were in fact a "ball" of macerated tissue, extremely soft and very difficult to handle, in sharp contrast with the wild type infection (Fig. 8F).

3.7. Differential expression of chitin synthase genes in PdchsVII mutants in response to infection

The expression of the different chs genes was compared during infection of parental CECT20796 and PDMG672 strains (Fig. 9). Gene expression during disease progression was induced in all the chs genes and in both strains. Expression was detected at $1 \mathrm{dpi}$ only in fruits infected with the parental strain, and not in all chs. Expression of Pdchsll, PdchsIV and PdchsVI could only be detected from $4 \mathrm{dpi}$. In the case of fruits infected with the mutant PDMG672, chs gene expression was in general lower than that of the parental strain. For instance, expression of $P d c h s / l$ could only be detected at $7 \mathrm{dpi}$ in fruits inoculated with PDMG672, at a time when fungal colonization is massive. Also, 
expression of $P d c h s / V$ and $P d c h s V I$ was significantly lower in the mutant at all the days. The only significant exception to this lower expression in the mutant was the MMD containing PdchsV, which was detected earlier. 


\section{Discussion}

The analysis and classification of the available PdChs sequences confirms the previously proposed third division in the classification of fungal Chs (Latgé, 2007). Our conclusion is based not only in phylogenetic clustering (Fig. 1A) but also in Pfam domain and TMH distribution (Fig. 1B). Robust phylogenetic reconstruction was favored by the inclusion of insect Chs (Merzendorfer, 2011) that are related to fungal class $\mathrm{VI}$ enzymes that conform the third division. This latter class $\mathrm{VI}$ is formed by proteins in the lower size limit of fungal Chs and that also only have a chitin synthase 2 Pfam domain. Also, the Division 2 is predicted to contain a cytochrome b5-like domain while the MMD chitin synthases contain a DEK C terminal-like domain, whose functional significance for the Chs activity of filamentous fungi still needs to be determined.

The newly identified class IV and VI genes showed the highest induction during growth in liquid PDB of the wild type strain of $P$. digitatum (Fig. 6A). In solid PDA, classes VI, II, and IV in this order were the most induced (Fig. 6B). Class IV chitin synthase genes are responsible of the bulk of chitin synthesis in vivo both in yeast and in filamentous fungi (Din et al., 1996; Specht et al., 1996), and the high transcription induction showed in all $P$. digitatum strains and growth conditions analyzed in this study are consistent with this predominant role. We had previously correlated the induction of $P d c h s / /$ with conidia production that occurs during growth in solid PDA, but not in liquid PDB, and pointed to a role of $P d c h s / l$ in conidiogenesis (Gandía et al., 2012). The analysis of expression of a representative gene from each class of Chs (Fig. 6) is consistent with a predominant role of $P d c h s / l$ in conidiogenesis. In the closely 
related A. nidulans, in situ staining patterns of AnchsA fused to a reporter protein showed that this class II Chs was mainly expressed within conidiophores (Fujiwara et al., 2000), and gene mutation resulted in a drastic reduction of the amount of conidia produced (Culp et al., 2000). From our data, however, it cannot be discarded an involvement in conidiation of classes IV, VI and VII genes. PdchsIV and PdchsVI are also among the more expressed during conidia production (Fig. 6B) and, together with Pdchsll, are repressed in the PDMG672 mutant during fruit infection (Fig. 9), under conditions in which there is no sporulation.

On the other hand, conidia production was lower in the PdchsVII disruption mutants than in the parental strain ( 40-60\%) at early times of growth (Fig. 2D), but we attributed this to their slow growth since it was mostly restored under osmotic stabilization. A. fumigatus CmsA (class V) and CsmB (class VII) mutants had a strong reduction of conidia production (more than 98\%), white coloration of colonies and abnormal conidiophores, indicating a critical role in the chitin biosynthesis of conidia and conidiogenesis (Jimenez-Ortigosa et al., 2012; Takeshita et al., 2006). P. digitatum PDMG672 and PDMG439 did not present abnormal conidiophores as seen under light microscopy and CFW staining (data not shown), and conidia production was only partly affected and restored in the presence of sorbitol. Therefore, even though the close phylogenetic relationship between Penicillium spp. and Aspergillus spp. (Marcet-Houben et al., 2012) (Fig. 1A), the class VII Chs of both fungi seems to have differences in their biological roles.

Results of this study showed a clear induction of expression of the MMD class $V$ and VII genes during fruit infection by the wild type $P$. digitatum (Fig. 9). This 
induction was comparatively more important than that produced during vegetative growth (Fig. 7). Classes V and VII have been shown to be important in various aspects of fungal pathogenesis (Cui et al., 2013; Garcerá-Teruel et al., 2004; Kim et al., 2009; Kong et al., 2012; Madrid et al., 2003; Martín-Urdíroz et al., 2008; Morcx et al., 2013; Odenbach et al., 2009; Takeshita et al., 2006; Werner et al., 2007). Therefore, we addressed the disruption of the MMD PdchsV and PdchsVII through ATMT to study their role in the pathogenesis and biology of the fruit-specific necrotroph $P$. digitatum. In this report, we describe the characterization of disruption mutants of $P d c h s V I I$ since the isolation of $P d c h s V$ mutants has not been possible. $P$. digitatum is not an amenable fungus to work with molecular genetic tools and the first studies in which reverse genetics is used have appeared recently (Wang et al., 2012; Zhang et al., 2013a; Zhang et al., 2013b; Zhang et al., 2013c). Gene disruption by homologous recombination has a very low frequency and in our experiments only two homologous recombinants were isolated from 799 transformants that were hygromycin resistant (i.e., $0.3 \%$ positives). One of the homologous recombinants (PDMG439) had an additional ectopic insertion of the gene disruption construct, yet it was included in our study because the phenotypic properties and gene expression analyses confirmed the similarities with the PDMG672 mutant.

We showed that the disruption of PdchsVII was not lethal and had an important effect on growth and development of mycelium. The PdchsVII mutants have profound CW alterations that have been observed in similar mutants of other fungi such as the presence of enlarged cells with increased CFW staining (Fig. 
3A) (Martín-Urdíroz et al., 2008; Takeshita et al., 2006; Werner et al., 2007), increased chitin content (Fig. 3B) (Cui et al., 2013; Cui et al., 2009), or increased susceptibility to compounds that affect CW (Fig. 4) (Cui et al., 2013;

Cui et al., 2009; Larson et al., 2011; Martín-Urdíroz et al., 2008). Adding sorbitol as osmotic stabilizer partially restored the growth of the mutant, further supporting the existence of defects in CW integrity. Inactivation of some chs genes have resulted in no observable change in phenotype in various filamentous fungi (Rogg et al., 2012; Roncero, 2002), suggesting at least some functional redundancy within the Division 1 of Chs. The phenotypic properties of chsVII mutants support the uniqueness of the class VII of Chs, since a differential phenotype was observed that could not be restored by the other Chs. It has been published recently that the MMD of class VII is not functionally equivalent to the MMD of class V (Tsuizaki et al., 2013) which underlines the different role of the shorter MMD domain and the different functionality of each class.

$P d c h s / l$ and also PdchsVI were the chs genes whose expression was mostly affected by the mutation of PdchsVII, as seen during vegetative growth (Fig. 6) and also after osmotic treatment (Fig. 7). The impressive $\sim 50$-fold induction of expression in Pdchs/l in the mutant during growth in liquid (Fig. 6A), as well as the increased expression of Pdchsl, Pdchs/V and PdchsVI, could be indicative of compensatory effects due to the absence of PdchsVII, and that would be also reflected in the high chitin content of the mutant. The mutation of the class VII enzyme in F. verticilloides induced the expression of class I, II III, V and VI genes (Larson et al., 2011), in a behavior only partly similar to our observations since the most induced gene in F. verticilloides corresponded to the other MMD- 
containing Chs5. A minor induction of expression of chs class II and class III was also observed in a B. cinerea class VII (Bcchs6) mutant (Cui et al., 2013). In A. nidulans, deletion of either the csmA (class V) or the $\operatorname{csmB}$ (class VII) increased the expression of the other MMD gene (Takeshita et al., 2006). In $P$. digitatum, a compensatory mechanism by the overexpression of the class $\mathrm{V}$ gene in the absence of a functional class VII gene was not observed, similarly to reports in F. oxysporum (Martín-Urdíroz et al., 2008). Therefore, different compensatory changes occur in chs mutants of different fungal species, which likely reflect singularities in the role of each Chs for the biology of each fungus. Chitin and chitin synthases are recognized as targets for novel fungicidal compounds (Latgé, 2007; Lenardon et al., 2010; Rogg et al., 2012). Nikkomycins, for instance, are existing Chs inhibitors in vitro that however have limited efficacy in vivo. We demonstrated that PdchsVII mutants have increased sensitivity to commercial fungicides of different mechanism of action: TBZ that inhibits microtubule assembly and IMZ that inhibits the biosynthetsis of ergosterol (Schmidt et al., 2006; Sun et al., 2011). The glucan synthase inhibitors echinocandins are also more active against $A$. fumigatus MMD Chs mutants (Jimenez-Ortigosa et al., 2012). Previous and ours data indicate that the increased susceptibility of MMD-Chs mutants to diverse fungicides is related to structural defects in the $\mathrm{CW}$, which facilitate the access of fungicides to the $\mathrm{CW} /$ cytoplasm. However, defects in the $\mathrm{CW}$ of Chs class V/VII mutants of $F$. verticilloides do not increase the low susceptibility of this fungus to nikkomycin $Z$, likely due to the low cell penetration properties that limit the efficacy of this fungicide (Larson et al., 2011). 
PAF26 is a cell-penetrating antifungal peptide that interacts with the fungal $\mathrm{CW}$, it is then internalized into the fungal cell and exerts its killing activity intracellularly (Harries et al., 2013; Muñoz et al., 2013a; Muñoz et al., 2013b; Muñoz et al., 2012). Exposure to PAF26 results in CW thickening and enlarged cells in P. digitatum (Muñoz et al., 2006) that resemble the alterations observed in fungal chs mutants, as well as in increased CFW staining in both $P$. digitatum and S. cerevisiae (López-García et al., 2010; Muñoz et al., 2006). Chitin and chitin synthase genes have been related with the activity of various antifungal proteins and peptides (Hagen et al., 2007; Martín-Urdiroz et al., 2009; Ouedraogo et al., 2011) and the increase of chitin content is a response of yeast and filamentous fungi to fortify the $\mathrm{CW}$ in the presence of antifungal peptides (Ouedraogo et al., 2011). We decided to explore the relation between chs genes and AMP action in $P$. digitatum. We had observed increased expression of various chs genes including PdchsVII after PAF26 exposure (Gandía and Marcos, unpublished observations). However, the susceptibility of the $P$. digitatum chsVII mutant to various AMP including PAF26 did not change both in inhibitory (Fig. 5B) and in fungicidal assays (data not shown). In $S$. cerevisiae, the three CHS were shown to be induced following treatment with the $A$. giganteus AFP but only mutation of $\mathrm{CHS} 1$ resulted in increased susceptibility to the antifungal protein (Ouedraogo et al., 2011). It is then possible that mutation of other Chs in $P$. digitatum might have relevance in the activity of PAF26 and other antifungal peptides. Nevertheless the lack of differential susceptibility of the PdchsVII mutant to these peptides and the increased sensitivity to common fungicides as TBZ or IMZ underscores the different mechanisms of action of these molecules. 
Characterization of mutants of class VII Chs -and the related class V- has shown almost every possible result regarding the requirement or not for pathogenicity or full virulence in different fungi, revealing complex (and not universal) roles of MMD Chs. In the human pathogen $A$. fumigatus the virulence of the mutant of the class VII enzyme $\Delta A f c h s E$ was not significantly affected, in spite of growth alterations and hyphal swellings in the mutant strain (AufauvreBrown et al., 1997). The Magnaporthe oryzae chs5 (class VII) gene was also dispensable for rice infection, while on the contrary mutation of chs6 (class V) completely abolished pathogenesis (Kong et al., 2012). A reverse situation occurs in $B$. cinerea, as the mutation of class VII gene but not of class $\mathrm{V}$ resulted in reduced virulence in a tomato detached leaf infection assay (Cui et al., 2013; Cui et al., 2009; Morcx et al., 2013). In the case of $F$. verticilloides both Chs were required for full virulence and the mutants still caused an attenuated infection and produced fumonisins on maize kernels (Larson et al., 2011). The most extreme result was found in Fusarium oxysporum since both mutants were non-pathogenic and did not cause symptoms on tomato plants (Madrid et al., 2003; Martín-Urdíroz et al., 2008). In addition, the class V enzyme is essential for pathogenicity of the maize pathogens Colletotrichum graminicola and Ustilago maydis (Weber et al., 2006; Werner et al., 2007). The PdchsVII mutation results in a reduction of virulence. In addition, although the mutant is able to macerate and colonize the fruit, the development of visible mycellium or sporulation during infection is greatly impaired. Previously, the $F$. oxysporum chsVb mutant that was not infective to plants showed a limited ability to macerate tomato fruit tissue at the area surrounding the inoculation site (Martín-Urdíroz et al., 2008), and it was considered to be non-pathogenic. 
Our data reveal a specific role of PdchsVII during the interaction with the host and infection because: (i) a dramatic impairment of fungal development of the mutant was basically observed only during infection (Figs. 2 and 8), and (ii) PdchsV and PdchsVII were among the genes more induced during infection but not during axenic growth (Figs 6 and 9).

Gene expression changes of the mutant during fruit infection offered additional information. The disruption of PdchsVII resulted in an overall reduction in the amount of chs transcripts. Transcripts from the chs most induced during axenic growth (PdchsII, PdchsIV and PdchsVI) dropped significantly during infection of the mutant. This low level of transcripts could be related to the impaired development of mycelium. In contrast PdchsV expression was the only gene that could be detected earlier in PDMG672 than in parental strain, perhaps as a result of compensatory mechanism between both MMD chitin synthases that occurs during early infection.

P. digitatum and other Penicillium spp. macerate fruit tissues through increased expression of lytic enzymes (González-Candelas et al., 2010; Sánchez-Torres and González-Candelas, 2003; Zhang et al., 2013a; Zhang et al., 2013b). The ability of the PdchsVII mutant to macerate host tissue indicates that the expression of genes coding for lytic enzymes is not affected, contrarily to other mutations that affect $P$. digitatum virulence (Zhang et al., 2013a; Zhang et al., 2013b). In fact, the phenotype shown by the mutant during fruit infection is different from other $P$. digitatum mutants affected in virulence that readily develop mycelium on fruits (Wang et al., 2012; Zhang et al., 2013a; Zhang et al., 2013b; Zhang et al., 2013c). Another factor that likely affects the virulence of the PdchsVII mutant is its high sensitivity to ROS (Fig. 4D), similarly to mutants 
in class V or VII Chs of F. oxysporum that are also sensitive to ROS and other plant defense compounds (Madrid et al., 2003; Martín-Urdíroz et al., 2008).

Citrus fruits are known to deploy ROS as a protective mechanism in response to fungal infection and the virulence of $P$. digitatum has been related to the ability of the fungus to neutralize this oxidant response of the fruit (Macarisin et al., 2007).

\section{Conclusions}

In summary, two additional Chs from classes IV and VI have been identified and characterized in this study, and add to the previously known Chs in $P$. digitatum. Disruption of the PdChsVII in P. digitatum has revealed its involvement in $\mathrm{CW}$ integrity, vegetative growth and fungal virulence, demonstrating a critical role in mycelium development and conidia production during host colonization. Our data support functional diversification and specialization among different fungal Chs, since the PdchsVII mutants presented clear phenotypic alterations and therefore the biological function of PdChsVII could not be fulfilled by the other Chs in spite of the existence of compensatory gene expression changes. Future research will focus on the disruption of the chitin synthase genes most affected by the inactivation of PdchsVII such as Pdchs/l and PdchsVI to establish their functional connections with the MMD Chs and their relevance in the biology of this economically important fungus. 


\section{Acknowledgments}

This work was funded by grants $\mathrm{BIO} 2009-12919$ and BIO2012-34381 from the "Ministerio de Economía y Competitividad" (MINECO, Spain) and ACOMP/2011/258 from "Conselleria d'Educaciò" (Generalitat Valenciana, Comunitat Valenciana, Spain). MG was hired by the JAE-DOC postdoc program (CSIC) and EH was recipient of a scholarship within the JAEPRE-DOC program (CSIC) funded both by the European FEDER funds. Plasmids pBHt2 and pGKO2 are a generous gift from Dr. Seogchan Kang (The Pennsylvania State University, PA, USA). Agrobacterium tumefaciens AGL-1 strain was kindly provided by Drs. Berta Alquézar and Leandro Peña (IVIA, Valencia, Spain). We acknowledge the collaboration of Dr. Lourdes Carmona (IATA, Valencia, Spain); the help with RNA extraction protocols of Dr. Luis González-Candelas, Dr. Mario López and Beatriz de la Fuente (IATA, Valencia, Spain); and the excellent technical assistance of M. José Pascual (IATA, Valencia, Spain). 
Table 1. Chitin Synthase Genes in Penicillium digitatum

\begin{tabular}{lclll}
\hline Class & Division & Gene name & Accession Number & Locus \\
\hline I & 1 & Pdchsl & JQ028871 / EKV04208.1 & PDIG_90720 \\
II & 1 & Pdchsll & JQ028872 / EKV15950.1 & PDIG_23050 \\
III & 1 & PdchsIII & JQ028873 / EKV16091.1 & PDIG_22170 \\
IV & 2 & PdchsIV & EKV04477.1 & PDIG_89090 \\
V & 2 & PdchsV & JQ028874 / EKV08102.1 & PDIG_69930 \\
VI & 3 & PdchsVI & EKV06080.1 & PDIG_78580 \\
VII & 2 & PdchsVII & JQ028874 / EKV08101.1 & PDIG_69920 \\
\hline
\end{tabular}




\section{References}

Aufauvre-Brown, A., Mellado, E., Gow, N. A. R., Holden, D. W., 1997.

Aspergillus fumigatus chsE: A gene related to $\mathrm{CHS} 3$ of Saccharomyces cerevisiae and important for hyphal growth and conidiophore development but not pathogenicity. Fungal Genet. Biol. 21, 141-152.

Ballester, A. R., Lafuente, M. T., González-Candelas, L., 2006. Spatial study of antioxidant enzymes, peroxidase and phenylalanine ammonia-lyase in the citrus fruit Penicillium digitatum interaction. Postharvest Biol. Technol. 39, 115-124.

Behr, J. B., 2011. Chitin Synthase, a Fungal Glycosyltransferase that Is a Valuable Antifungal Target. Chimia. 65, 49-53.

Cui, Z., Wang, Y., Lei, N., Wang, K., Zhu, T., 2013. Botrytis cinerea chitin synthase $\mathrm{BcChsVI}$ is required for normal growth and pathogenicity. Curr. Genet. 59, 119-128.

Cui, Z. F., Ding, Z. K., Yang, X., Wang, K., Zhu, T. H., 2009. Gene disruption and characterization of a class $V$ chitin synthase in Botrytis cinerea. Can. J. Microbiol. 55, 1267-1274.

Culp, D. W., Dodge, C. L., Miao, Y., Li, L., Sag-Ozkal, D., Borgia, P. T., 2000. The chsA gene from Aspergillus nidulans is necessary for maximal conidiation. FEMS Microbiol. Lett. 182, 349-353.

Choquer, M., Boccara, M., Goncalves, I. R., Soulie, M. C., Vidal-Cros, A., 2004. Survey of the Botrytis cinerea chitin synthase multigenic family through the analysis of six euascomycetes genomes. Eur. J. Biochem. 271, 21532164.

Devany, M., Kotharu, N. P., Matsuo, H., 2004. Solution NMR structure of the Cterminal domain of the human protein DEK. Protein Sci. 13, 2252-2259.

Din, A. B., Specht, C. A., Robbins, P. W., Yarden, O., 1996. Chs-4 , a class IV chitin synthase gene from Neurospora crassa. Mol. Gen. Genet. 250, 214-222.

Finn, R. D., Clements, J., Eddy, S. R., 2011. HMMER web server: Interactive sequence similarity searching. Nucleic Acids Res. 39, W29-W37. 
Fujiwara, M., Ichinomiya, M., Motoyama, T., Horiuchi, H., Ohta, A., Takagi, M., 2000. Evidence that the Aspergillus nidulans class I and class II chitin synthase genes, chs $C$ and $c h s A$, share critical roles in hyphal wall integrity and conidiophore development. J. Biochem. 127, 359-366.

Gandía, M., Harries, E., Marcos, J. F., 2012. Identification and characterization of chitin synthase genes in the postharvest citrus fruit pathogen Penicillium digitatum. Fungal Biol. 116, 654-664.

Garcerá-Teruel, A., Xoconostle-Cázares, B., Rosas-Quijano, R., Ortiz, L., LeónRamirez, C., Specht, C. A., Sentandreu, R., Ruiz-Herrera, J., 2004. Loss of virulence in Ustilago maydis by Umchs6 gene disruption. Res. Microbiol. 155, 87-97.

González-Candelas, L., Alamar, S., Sánchez-Torres, P., Zacarías, L., Marcos, J. F., 2010. A transcriptomic approach highlights induction of secondary metabolism in citrus fruit in response to Penicillium digitatum infection. BMC Plant Biol. 10, 194.

Hagen, S., Marx, F., Ram, A. F., Meyer, V., 2007. The antifungal protein AFP from Aspergillus giganteus inhibits chitin synthesis in sensitive fungi. Appl. Environ. Microbiol. 73, 2128-2134.

Harries, E., Carmona, L., Muñoz, A., Ibeas, J. I., Read, N. D., Gandía, M., Marcos, J. F., 2013. Genes involved in protein glycosylation determine the activity and cell internalization of the antifungal peptide PAF26 in Saccharomyces cerevisiae. Fungal Genet. Biol. 58-59, 105-115.

Holmes, G. J., Eckert, J. W., 1999. Sensitivity of Penicillium digitatum and $P$. italicum to postharvest citrus fungicides in California. Phytopathology. 89, 716-721.

Horiuchi, H., Fujiwara, M., Yamashita, S., Ohta, A., Takagi, M., 1999. Proliferation of intrahyphal hyphae caused by disruption of $\operatorname{csmA}$, which encodes a class $\mathrm{V}$ chitin synthase with a myosin motor-like domain in Aspergillus nidulans. J. Bacteriol. 181, 3721-3729.

Jang, W. S., Li, X. W. S., Sun, J. N. N., Edgerton, M., 2008. The P-113 fragment of Histatin 5 requires a specific peptide sequence for intracellular translocation in Candida albicans, which is independent of cell wall binding. Antimicrob. Agents Chemother. 52, 497-504. 
Jimenez-Ortigosa, C., Aimanianda, V., Muszkieta, L., Mouyna, I., Alsteens, D., Pire, S., Beau, R., Krappmann, S., Beauvais, A., Dufrêne, Y. F., Roncero, C., Latgé, J. P., 2012. Chitin synthases with a myosin motor-like domain control the resistance of Aspergillus fumigatus to echinocandins.

Antimicrob. Agents Chemother. 56, 6121-6131.

Khang, C. H., Park, S. Y., Lee, Y. H., Kang, S. C., 2005. A dual selection based, targeted gene replacement tool for Magnaporthe grisea and Fusarium oxysporum. Fungal Genet. Biol. 42, 483-492.

Khang, C. H., Park, S. Y., Rho, H. S., Lee, Y. H., Kang, S., 2006. Filamentous Fungi (Magnaporthe grisea and Fusarium oxysporum). Methods Mol. Biol. 344, 403-420.

Kim, J. E., Lee, H. J., Lee, J. K., Kim, K. W., Yun, S. H., Shim, W. B., Lee, Y. W., 2009. Gibberella zeae chitin synthase genes, GzCHS5 and GzCHS7, are required for hyphal growth, perithecia formation, and pathogenicity. Curr. Genet. 55, 449-459.

Kombrink, A., Sánchez-Vallet, A., Thomma, B. P. H. J., 2011. The role of chitin detection in plant-pathogen interactions. Microb. Infect. 13, 1168-1176.

Kong, L.-A., Yang, J., Li, G.-T., Qi, L.-L., Zhang, Y.-J., Wang, C.-F., Zhao, W.S., Xu, J.-R., Peng, Y.-L., 2012. Different Chitin Synthase Genes Are Required for Various Developmental and Plant Infection Processes in the Rice Blast Fungus Magnaporthe oryzae. PLoS Pathog. 8, e1002526.

Larson, T. M., Kendra, D. F., Busman, M., Brown, D. W., 2011. Fusarium verticillioides chitin synthases $\mathrm{CHS} 5$ and $\mathrm{CHS7}$ are required for normal growth and pathogenicity. Curr. Genet. 57, 177-189.

Latgé, J. P., 2007. The cell wall: A carbohydrate armour for the fungal cell. Mol. Microbiol. 66, 279-290.

Lenardon, M. D., Munro, C. A., Gow, N. A. R., 2010. Chitin synthesis and fungal pathogenesis. Curr. Opin. Microbiol. 13, 416-423.

López-García, B., Gandía, M., Muñoz, A., Carmona, L., Marcos, J. F., 2010. A genomic approach highlights common and diverse effects and determinants of susceptibility on the yeast Saccharomyces cerevisiae exposed to distinct antimicrobial peptides. BMC Microbiol. 10, 289. 
López-García, B., González-Candelas, L., Pérez-Payá, E., Marcos, J. F., 2000. Identification and characterization of a hexapeptide with activity against phytopathogenic fungi that cause postharvest decay in fruits. Mol. PlantMicrobe Interact. 13, 837-846.

Macarisin, D., Cohen, L., Eick, A., Rafael, G., Belausov, E., Wisniewski, M., Droby, S., 2007. Penicillium digitatum suppresses production of hydrogen peroxide in host tissue during infection of citrus fruit. Phytopathology. 97, 1491-1500.

Madrid, M. P., Di Pietro, A., Roncero, M. I. G., 2003. Class V chitin synthase determines pathogenesis in the vascular wilt fungus Fusarium oxysporum and mediates resistance to plant defence compounds. Mol. Microbiol. 47, 257-266.

Marcet-Houben, M., Ballester, A. R., de la Fuente, B., Harries, E., Marcos, J. F., González-Candelas, L., Gabaldón, T., 2012. Genome sequence of the necrotrophic fungus Penicillium digitatum, the main postharvest pathogen of citrus. BMC Genomics. 13, 646.

Marcos, J. F., Muñoz, A., Pérez-Payá, E., Misra, S., López-García, B., 2008. Identification and Rational Design of Novel Antimicrobial Peptides for Plant Protection. Annu. Rev. Phytopathol. 46, 273-301.

Martín-Urdiroz, M., Martínez-Rocha, A. L., Di Pietro, A., Martínez del Pozo, A., Roncero, M. I. G., 2009. Differential toxicity of antifungal protein AFP against mutants of Fusarium oxysporum. Int. Microbiol. 12, 115-121. Martín-Urdíroz, M., Roncero, M. I., González-Reyes, J. A., Ruiz-Roldán, C., 2008. ChsVb, a class VII chitin synthase involved in septation, is critical for pathogenicity in Fusarium oxysporum. Eukaryot. Cell. 7, 112-121. Merzendorfer, H., 2011. The cellular basis of chitin synthesis in fungi and insects: Common principles and differences. Eur. J. Cell Biol. 90, 759769.

Michielse, C. B., Hooykaas, P. J. J., van den Hondel, C. A. M. J., Ram, A. F. J., 2008. Agrobacterium-mediated transformation of the filamentous fungus Aspergillus awamori Nat. Protoc. 3, 1671-1678.

Morcx, S., Kunz, C., Choquer, M., Assie, S., Blondet, E., Simond-Côte, E., Gajek, K., Chapeland-Leclerc, F., Expert, D., Soulie, M.-C., 2013. 
Disruption of Bcchs4, Bcchs6 or Bcchs7 chitin synthase genes in Botrytis cinerea and the essential role of class VI chitin synthase (Bcchs6). Fungal Genet. Biol. 52, 1-8.

Muñoz, A., Gandía, M., Harries, E., Carmona, L., Read, N. D., Marcos, J. F., 2013a. Understanding the mechanism of action of cell-penetrating antifungal peptides using the rationally designed hexapeptide PAF26 as a model. Fungal Biol. Rev. 26, 146-155.

Muñoz, A., Harries, E., Contreras-Valenzuela, A., Carmona, L., Read, N. D., Marcos, J. F., 2013b. Two Functional Motifs Define the Interaction, Internalization and Toxicity of the Cell-Penetrating Antifungal Peptide PAF26 on Fungal Cells. PLoS ONE. 8.

Muñoz, A., López-García, B., Marcos, J. F., 2006. Studies on the mode of action of the antifungal hexapeptide PAF26. Antimicrob. Agents Chemother. 50, 3847-3855.

Muñoz, A., López-García, B., Veyrat, A., González-Candelas, L., Marcos, J. F., 2011. Comparative analysis of the sensitivity to distinct antimicrobials among Penicillium spp. causing fruit postharvest decay. Phytopathol. Mediterr. 50, 392-407.

Muñoz, A., Marcos, J. F., Read, N. D., 2012. Concentration-dependent mechanisms of cell penetration and killing by the de novo designed antifungal hexapeptide PAF26. Mol. Microbiol. 85, 89-106.

Nair, R., Roy, I., Bucke, C., Keshavarz, T., 2009. Quantitative PCR study on the mode of action of oligosaccharide elicitors on penicillin $\mathrm{G}$ production by Penicillium chrysogenum. J. Appl. Microbiol. 107, 1131-1139.

Niño-Vega, G. A., Carrero, L., San-Blas, G., 2004. Isolation of the CHS4 gene of Paracoccidioides brasiliensis and its accommodation in a new class of chitin synthases. Med. Mycol. 42, 51-57.

Odenbach, D., Thines, E., Anke, H., Foster, A. J., 2009. The Magnaporthe grisea class VII chitin synthase is required for normal appressorial development and function. Mol. Plant Pathol. 10, 81-94.

Ouedraogo, J. P., Hagen, S., Spielvogel, A., Engelhardt, S., Meyer, V., 2011. Survival Strategies of Yeast and Filamentous Fungi against the Antifungal Protein AFP. J. Biol. Chem. 286, 13859-13868. 
Pfaffl, M. W., Horgan, G. W., Dempfle, L., 2002. Relative expression software tool (REST) for group-wise comparison and statistical analysis of relative expression results in real-time PCR. Nucleic Acids Res. 30, e36.

Rodrigo, M. J., Marcos, J. F., Zacarías, L., 2004. Biochemical and molecular analysis of carotenoid biosynthesis in flavedo of orange (Citrus sinensis L.) during fruit development and maturation. J. Agric. Food Chem. 52, 6724-6731.

Rogg, L. E., Fortwendel, J. R., Juvvadi, P. R., Steinbach, W. J., 2012.

Regulation of expression, activity and localization of fungal chitin synthases. Med. Mycol. 50, 2-17.

Roncero, C., 2002. The genetic complexity of chitin synthesis in fungi. Curr. Genet. 41, 367-378.

Saitou, N., Nei, M., 1987. The neighbor-joining method: A new method for reconstructing phylogenetic trees. Mol. Biol. Evol. 4, 406-425.

Sánchez-Torres, P., González-Candelas, L., 2003. Isolation and characterization of genes differentially expressed during the interaction between apple fruit and Penicillium expansum. Mol. Plant Pathol. 4, 447457.

Sanzani, S. M., Schena, L., Nigro, F., De Girolamo, A., Ippolito, A., 2009. Effect of quercentin and umbelliferone on the transcript level of Penicillium expansum genes involved in patulin biosynthesis. Eur. J. Plant Pathol. 125, 223-233.

Schmidt, L. S., Ghosoph, J. M., Margosan, D. A., Smilanick, J. L., 2006. Mutation at $\beta$-tubulin codon 200 indicated thiabendazole resistance in Penicillium digitatum collected from California citrus packinghouses. Plant Dis. 90, 765-770.

Schuster, M., Treitschke, S., Kilaru, S., Molloy, J., Harmer, N. J., Steinberg, G., 2012. Myosin-5, kinesin-1 and myosin-17 cooperate in secretion of fungal chitin synthase. EMBO J. 31, 214-227.

Specht, C. A., Liu, Y., Robbins, P. W., Bulawa, C. E., lartchouk, N., Winter, K. R., Riggle, P. J., Rhodes, J. C., Dodge, C. L., Culp, D. W., Borgia, P. T., 1996. The chsD and chsE Genes of Aspergillus nidulans and their roles in chitin synthesis. Fungal Genet. Biol. 20, 153-167. 
Steinberg, G., 2011. Motors in fungal morphogenesis: Cooperation versus competition. Curr. Opin. Microbiol. 14, 660-667.

Steiner, H., Hultmark, D., Engstrom, A., Bennich, H., Boman, H. G., 1981. Sequence and specificity of 2 anti-bacterial proteins involved in insect immunity. Nature. 292, 246-248.

Sun, X., Wang, J., Feng, D., Ma, Z., Li, H., 2011. PdCYP51B, a new putative

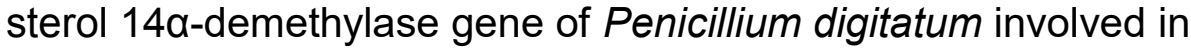
resistance to imazalil and other fungicides inhibiting ergosterol synthesis. Appl. Microbiol. Biotechnol. 91, 1107-1119.

Szewczyk, E., Nayak, T., Oakley, C. E., Edgerton, H., Xiong, Y., Taheri-Talesh, N., Osmani, S. A., Oakley, B. R., 2006. Fusion PCR and gene targeting in Aspergillus nidulans. Nat. Protoc. 1, 3111-3120.

Takeshita, N., Ohta, A., Horiuchi, H., 2005. CsmA, a class V chitin synthase with a myosin motor-like domain, is localized through direct interaction with the actin cytoskeleton in Aspergillus nidulans. Mol. Biol. Cell. 16, 1961-1970.

Takeshita, N., Yamashita, S., Ohta, A., Horiuchi, H., 2006. Aspergillus nidulans class V and VI chitin synthases CsmA and CsmB, each with a myosin motor-like domain, perform compensatory functions that are essential for hyphal tip growth. Mol. Microbiol. 59, 1380-1394.

Tamura, K., Peterson, D., Peterson, N., Stecher, G., Nei, M., Kumar, S., 2011. MEGA5: Molecular Evolutionary Genetics Analysis using Maximum Likelihood, Evolutionary Distance, and Maximum Parsimony Methods. Mol. Biol. Evol. 28, 2731-2739.

Terwillinger, T. C., Eisenberg, D., 1982. The structure of melittin. II. Interpretation of the structure. J. Biol. Chem. 257, 6016-6022.

Thompson, J. D., Higgins, D. G., Gibson, T. J., 1994. Clustal-W - Improving the Sensitivity of Progressive Multiple Sequence Alignment Through Sequence Weighting, Position-Specific Gap Penalties and Weight Matrix Choice. Nucleic Acids Res. 22, 4673-4680.

Treitschke, S., Doehlemann, G., Schuster, M., Steinberg, G., 2010. The Myosin Motor Domain of Fungal Chitin Synthase V Is Dispensable for Vesicle 
Motility but Required for Virulence of the Maize Pathogen Ustilago maydis. Plant Cell. 22, 2476-2494.

Tsuizaki, M., Ohta, A., Horiuchi, H., 2013. Myosin motor-like domain of class VI chitin synthase csmB of Aspergillus nidulans is not functionally equivalent to that of class $V$ chitin synthase csmA. Biosci. Biotechnol. Biochem. 77, 369-374.

Vandesompele, J., De Preter, K., Pattyn, F., Poppe, B., Van Roy, N., De Paepe, A., Speleman, F., 2002. Accurate normalization of real-time quantitative RT-PCR data by geometric averaging of multiple internal control genes. Genome Biol. 3, 0034.

Wang, J. Y., Sun, X. P., Lin, L. Y., Zhang, T. Y., Ma, Z. H., Li, H. Y., 2012. PdMfs1, a major facilitator superfamily transporter from Penicillium digitatum, is partially involved in the imazalil-resistance and pathogenicity. African Journal of Microbiology Research. 6, 95-105.

Weber, I., Assmann, D., Thines, E., Steinberg, G., 2006. Polar localizing Class $\mathrm{V}$ myosin chitin synthases are essential during early plant infection in the plant pathogenic fungus Ustilago maydis. Plant Cell. 18, 225-242.

Werner, S., Sugui, J. A., Steinberg, G., Deising, H. B., 2007. A Chitin synthase with a myosin-like motor domain is essential for hyphal growth, appressorium differentiation, and pathogenicity of the maize anthracnose fungus Colletotrichum graminicola. Mol. Plant-Microbe Interact. 20, 15551567.

Zhang, T., Sun, X., Xu, Q., Candelas, L. G., Li, H., 2013a. The pH signaling transcription factor PacC is required for full virulence in Penicillium digitatum. Appl. Microbiol. Biotechnol., 1-12.

Zhang, T., Sun, X., Xu, Q., Zhu, C., Li, Q., Li, H., 2013b. PdSNF1, a sucrose non-fermenting protein kinase gene, is required for Penicillium digitatum conidiation and virulence. Appl. Microbiol. Biotechnol., 1-13.

Zhang, T. Y., Xu, Q., Sun, X. P., Li, H. Y., 2013c. The calcineurin-responsive transcription factor $\mathrm{Crz} 1$ is required for conidation, full virulence and DMI resistance in Penicillium digitatum. Microbiol. Res. 168, 211-222. 


\section{Figure Legends}

Fig. 1. Phylogenetic analysis and domain representation of $P$. digitatum Chs proteins. (A) Neighbor joining tree of Chs protein sequences from yeasts, insects and filamentous fungi. The phylogenetic analysis was conducted using MEGA 5.2. Bootstrap test of phylogeny was performed with 10,000 replicates and bootstrap values are shown at the nodes of each proposed Chs class. Sequences characterized in this study are in bold. Three divisions and seven classes of Chs are distinguished. Supplemental Table 1 includes accession number of all sequences used in this analysis. (B) Schematic representation of all domains in Chs protein described in this study. Transmembrane helices (TMH) are shown as vertical black lines. The boxes in grey show the Pfam domains 1N (PF08407), C1 (PF01644) and C2 (PF03142) chitin synthase domains; in white the MMD myosin motor domains (PF00063); in black the cytochrome b5-like heme/steroid binding domain (PF00173); and in stripped pattern the DEK C terminal domain (PF08766). Black line with circular symbol indicates the conserved QRRRW motif present in all Chs enzymes. The P-loop conserved motif characteristics of MMD domain in Class V Chs is shown as a black line with a triangle.

Fig. 2. Growth and conidia production of $P$. digitatum strains. Strains shown are: parental CECT20796, ectopic strain PDMG612, and $\Delta P d c h s V I I$ disruption strains PDMG672 and PDMG439. (A) Colony morphology after 5 days of growth at $24{ }^{\circ} \mathrm{C}$ in PDA plates. (B) Colony diameter from 3 to 10 days of growth at $24^{\circ} \mathrm{C}$ on PDA (continuous lines) or PDA supplemented with $1.2 \mathrm{M}$ sorbitol (dashed lines). (C) Growth of serial dilutions of conidia (indicated at the bottom) 
on PDA or PDA supplemented with 1.2 M sorbitol as osmotic stabilizer. (D) Conidia production of parental and PDMG672 strain on PDA (continuous lines) or PDA supplemented with 1.2 M sorbitol (dashed lines).

Fig. 3. Morphological changes and chitin content in P. digitatum PdchsVII disruption strains. (A) Fluorescence microscopy of $P$. digitatum strains. Representative images of CFW staining from bright field (left column) and fluorescence microscopy (right) are shown of the parental strain CECT20796 and disruption strains PDMG672 and PDMG439. White arrows indicate presence in disruption strains of balloon-like cell enlargements that are intensively CFW stained. (B) Chitin content analysis of the parental and disruption strains determined as $\mathrm{N}$-acetyl-D-glucosamine (GlcNAc) released per dry weight of tissue. Data are expressed as means \pm standard deviation (SD) of four replicates. Asterisk indicates statistically significant difference with the parental strain, as determined by t-test analysis $(p<0.05)$.

Fig. 4. Sensitivity of $P$. digitatum strains to different concentrations of CFW (A), SDS (B), to different growth temperatures $(\mathrm{C})$, or to different concentrations of $\mathrm{H}_{2} \mathrm{O}_{2}$ (D). Serial dilutions of conidia of each strain were applied as indicated. Other details as in Fig. 2.

Fig. 5: Sensitivity of $P$. digitatum strains to the fungicides thiabendazole (TBZ) or imazalil (IMZ) (A), or to the antifungal peptide PAF26 (B). Serial $1 / 4$ dilutions of conidia of each strain $\left(1.56 \times 10^{4}\right.$ to $\left.9.75 \times 10^{2}\right)$ were applied as indicated.

Fig. 6. Relative expression of P.digitatum chs genes in parental CECT20796 (white bars) and disruption strain PDMG672 (grey and striped bars) over time of growth in culture. (A) Graph shows relative expression at 1, 3 and 7 days of growth in liquid PDB. Gene expression was normalized independently for each 
gene to the expression at day 1 of parental strain. (B) Graph shows relative expression at 2, 4 and 7 days of growth in solid PDA. Gene expression was normalized independently for each gene to the expression at day 2 of parental strain. In all cases bars show the mean \pm standard error (SE) of three replicates. Symbols indicate statistical significance $(p<0.05)$ as follows: differences at each day with the reference condition (first day of the parental strain) are labeled with empty circles (up-regulation) or full circles (downregulation); differences of disruption strain with regard to parental strain at the same day are labeled with empty inverted triangles (up-regulation) or full inverted triangles (down-regulation). n.d, expression not detected in these samples.

Fig. 7. Relative expression of P.digitatum chs genes in parental CECT20796 (white bars) and disruption strain PDMG672 (grey and striped bars) in solid PDA plates $(\mathrm{C})$ and in response to high osmolarity (PDA plates supplemented with 1.2 M sorbitol) (S). Gene expression was normalized independently for each gene to the value at PDA control plates of parental strain. Other details as in Fig. 6.

Fig. 8. Virulence assays of $P$. digitatum strains on orange fruits. $(A)$ Incidence of infection caused by parental CECT20796, ectopic PDMG612 and disruption strains PDMG672 and PDMG439, at low inoculum dose $\left(10^{4}\right.$ conidia/mL). Data indicate percentage of infected wounds (mean value \pm SD) at each day post inoculation. (B) Incidence of infection caused by parental CECT20796 or disruption strain PDMG672, at high inoculum dose $\left(10^{6}\right.$ conidia/mL). (C) Diameter of lesions on fruits from the experiment show in (B). (D) Relative quantification of fungal biomass at different days post infection from the 
experiment shown in (B) using qRT-PCR and $P$. digitatum $\beta$-tubulin as reference housekeeping gene. (E) Percentage of sporulated wounds on fruits from the experiment shown in (B). (F) Representative images of fruits infected with parental and PDMG672 strains at 7 days post inoculation from the experiment shown in (B). Note the absence of sporulation in fruits infected with $\Delta P d c h s V I I$ disruption strain PDMG672.

Fig. 9. Relative expression of P.digitatum chs genes in parental CECT20796 (white bars) and disruption strain PDMG672 (grey and striped bars) during infection of citrus fruit at high inoculum dose $\left(10^{6}\right.$ conidia/mL). Graph shows relative expression at 1, 2, 4 or 7 days after inoculation. Gene expression was normalized independently for each gene to the first day at which expression in parental strain was detected: day 1 for Pdchsl, PdchsIII and PdchsVII and day 4 for Pdchsll, PdchsIV, PdchsV and PdchsVI. Other details as in Fig. 6. 
Figure 1 (Gandía et al., 2013)

A

Class III

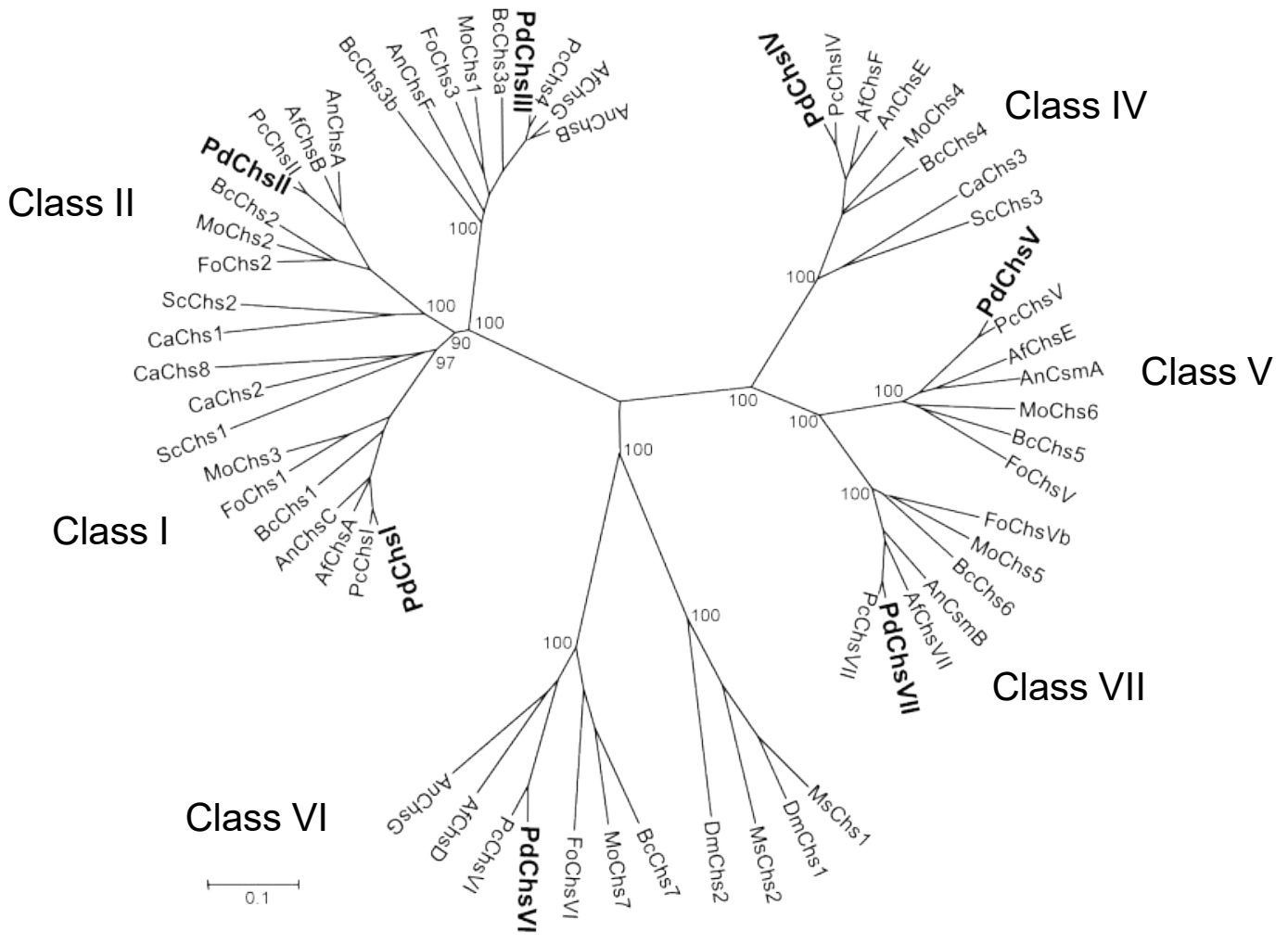

B

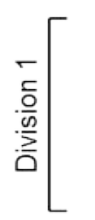
PdChsl (914 aa) PdChsll (1014 aa) PdChsllI (914 aa)

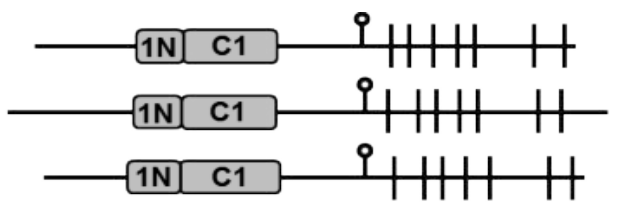

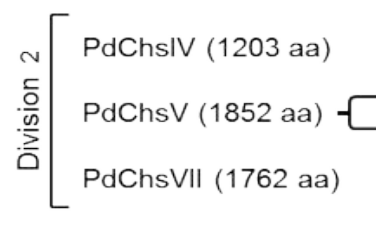
$\stackrel{m}{\ddot{a}}[$ 
Figure 2 (Gandía et al., 2013)

A

CECT20796 PDMG612 PDMG672 PDMG439
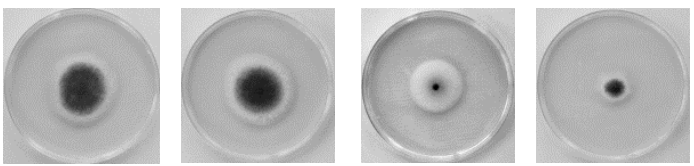

B

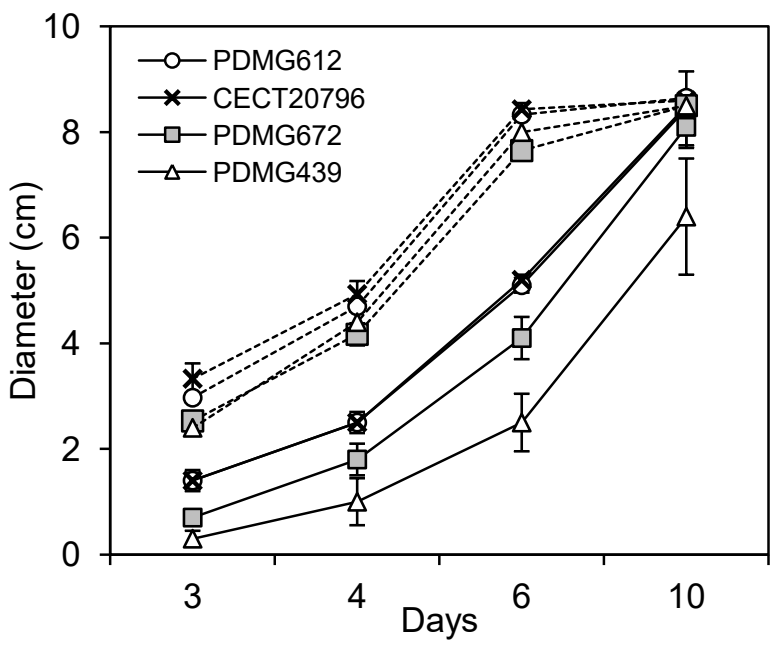

C

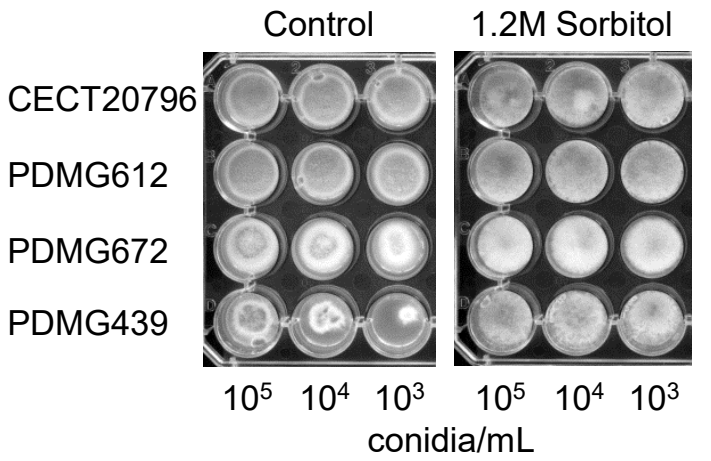

D

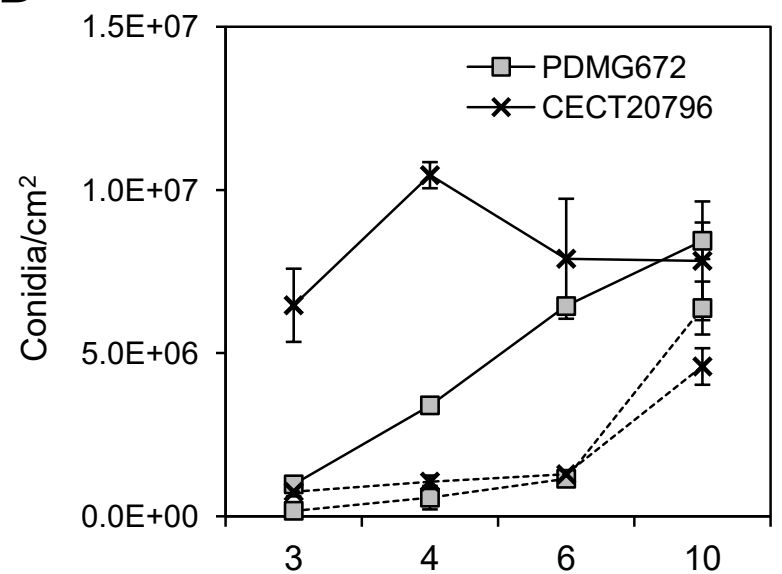


Figure 3 (Gandía et al., 2013)

A
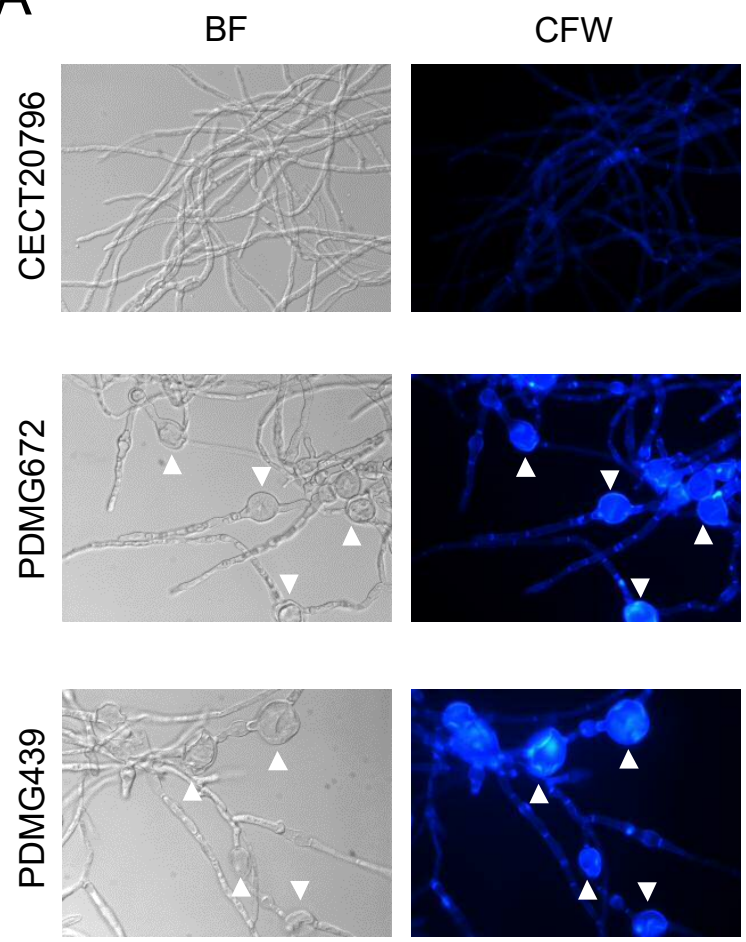

B

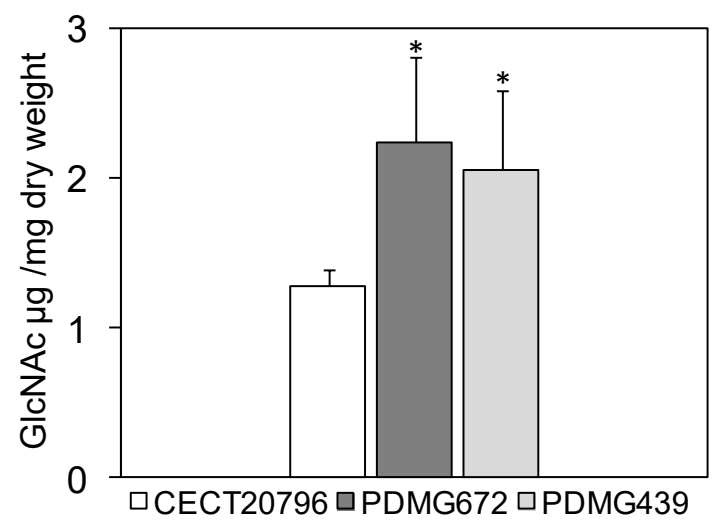


Figure 4 (Gandía et al., 2013)

A

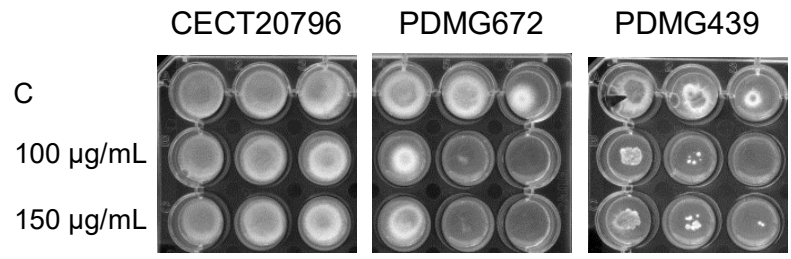

B

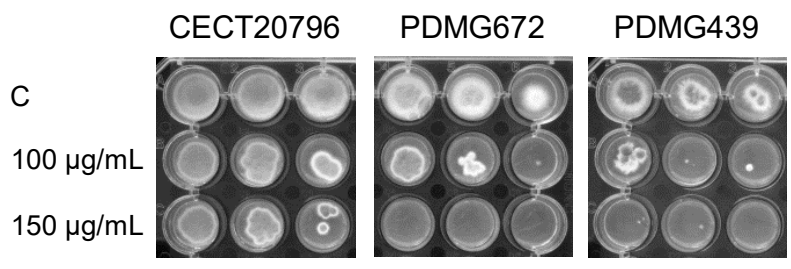

C

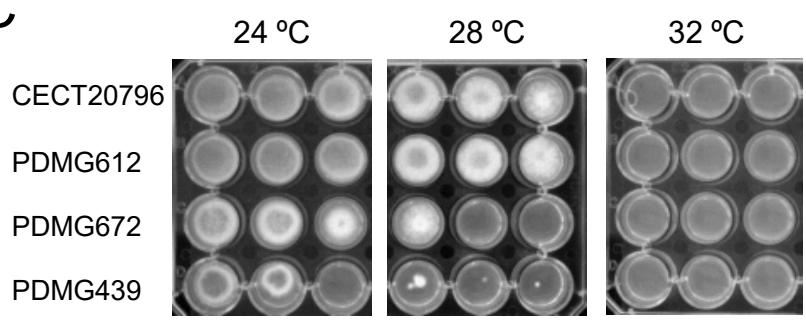

D

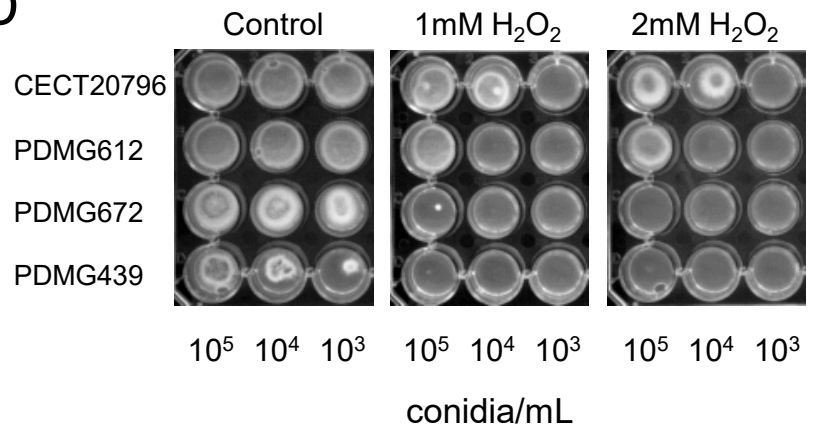


Figure 5 (Gandía et al., 2013)

A

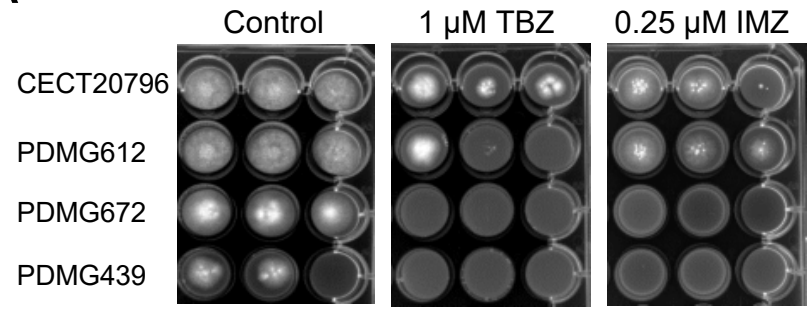

B

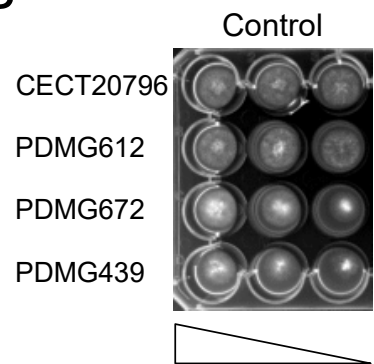

PAF26

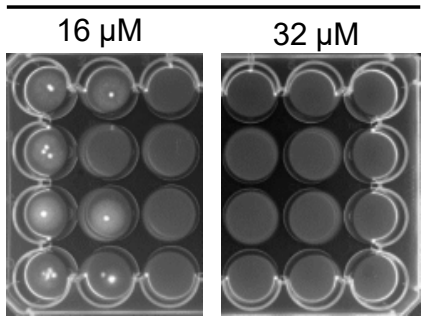


Figure 6 (Gandía et al., 2013)

A

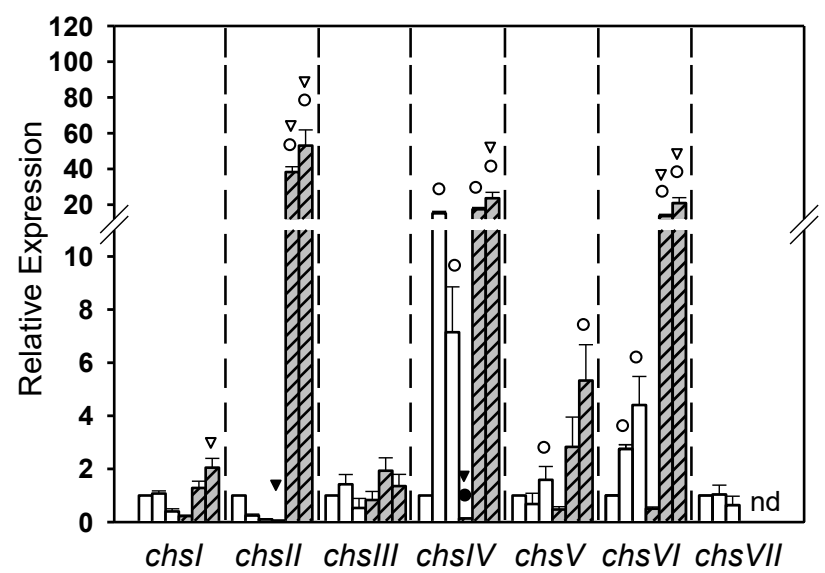

B

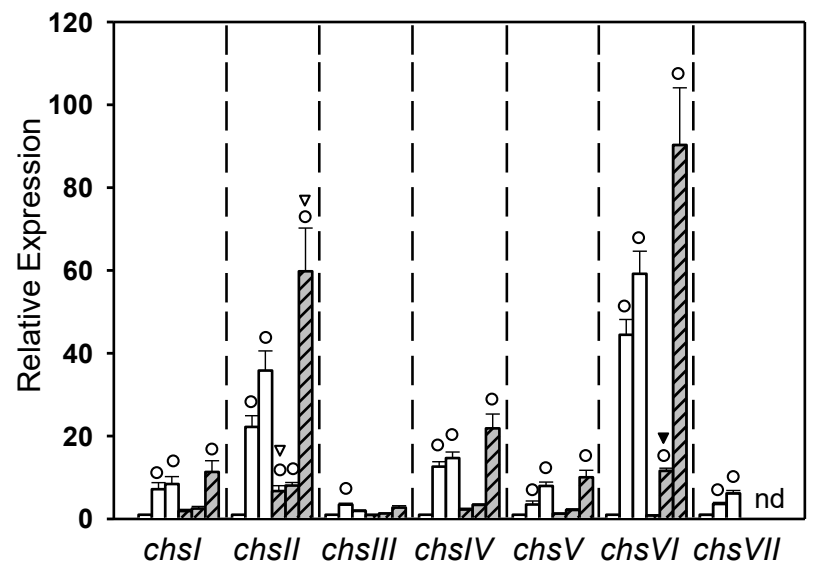


Figure 7 (Gandía et al., 2013)

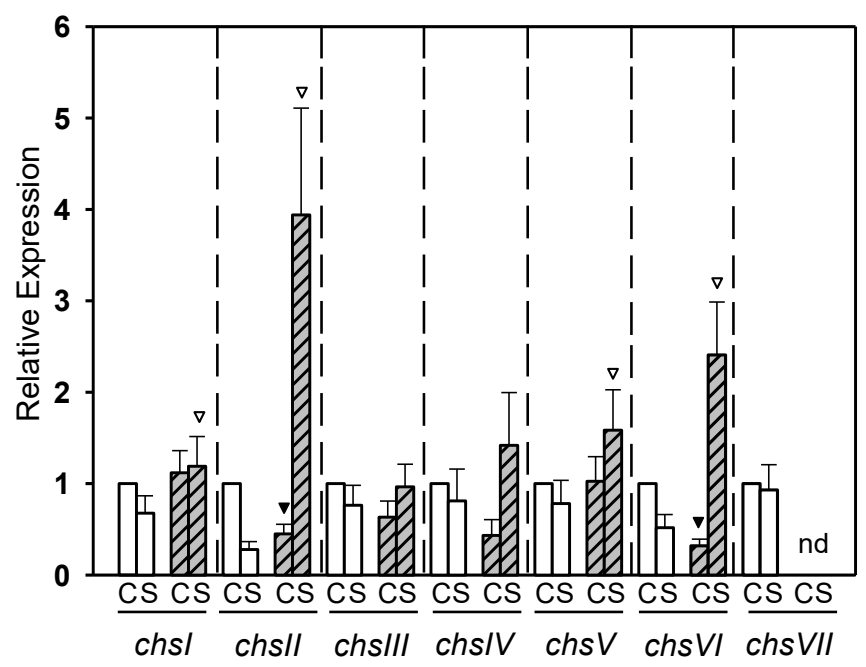


Figure 8 (Gandía et al., 2013)

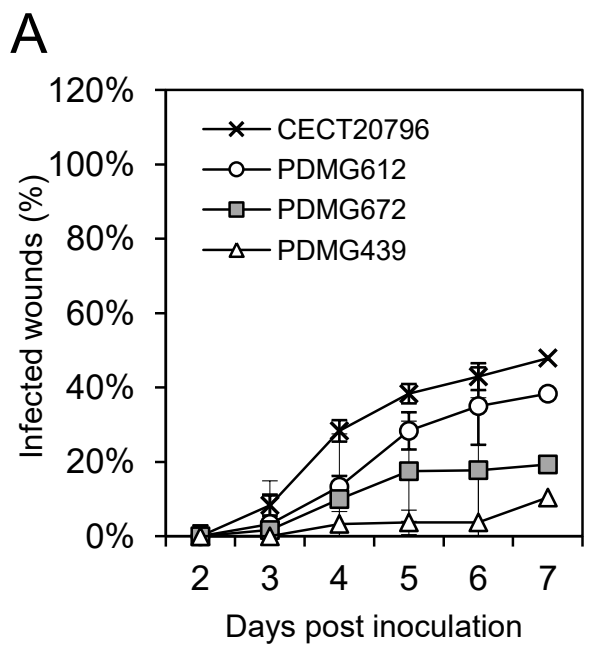

B

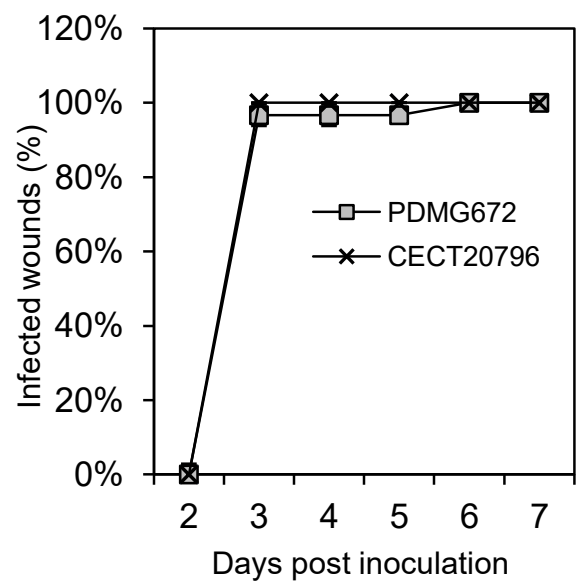

C
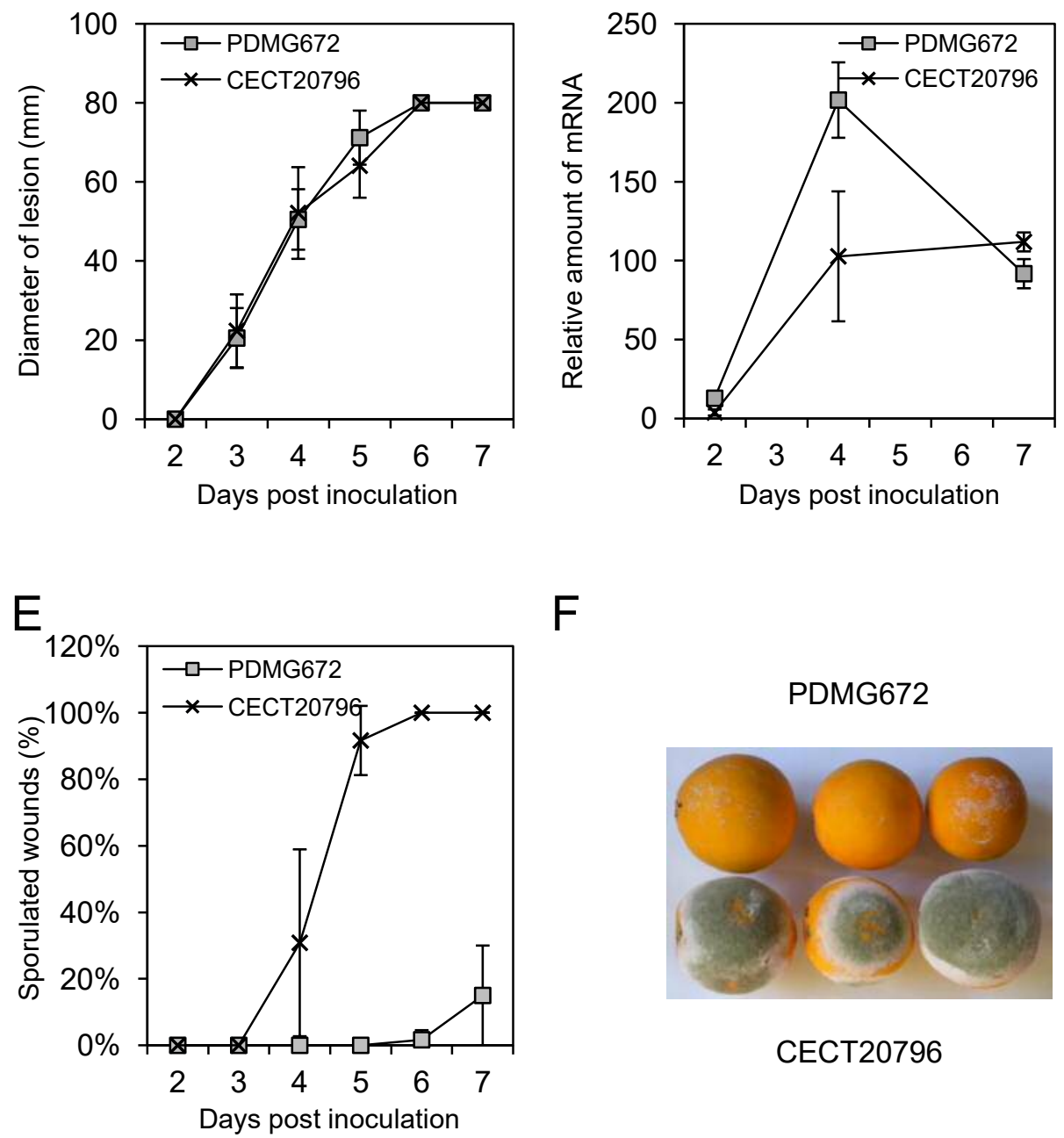

F

PDMG672

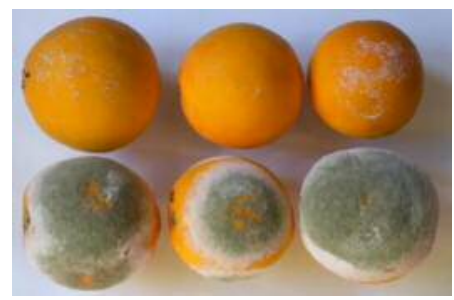

CECT20796 
Figure 9 (Gandía et al., 2013)

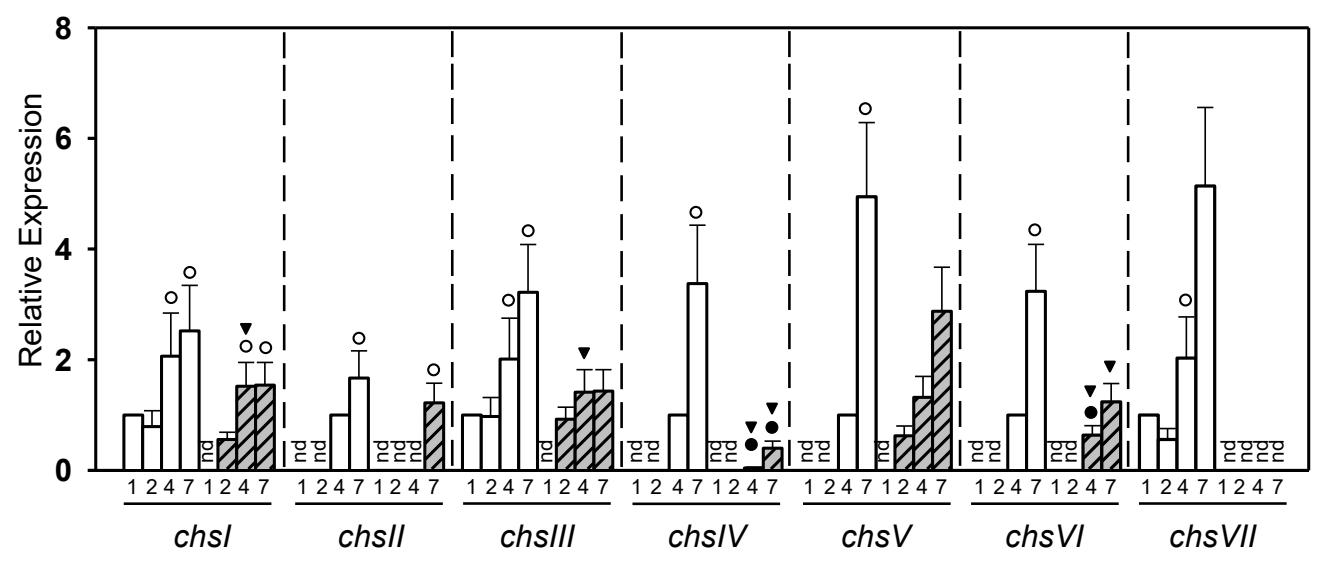

